\title{
Implementing the ESC/ERS pulmonary hypertension guidelines: real-life cases from a national referral centre
}

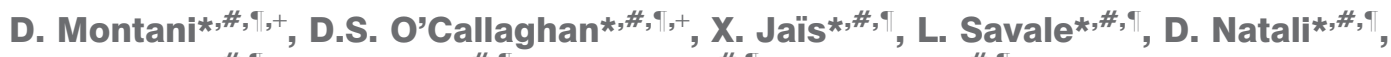

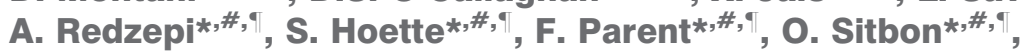



ABSTRACT: Pulmonary hypertension (PH) comprises a heterogeneous group of disorders characterised by increased pulmonary vascular resistance that results in progressive right ventricular failure. In order to translate current evidence into routine clinical practice, the European Society of Cardiology (ESC) and the European Respiratory Society (ERS) have recently jointly proposed evidence-based guidelines for the optimal management of different $\mathrm{PH}$ patient groups. This article describes a series of clinical cases of $\mathrm{PH}$ due to various aetiologies that were referred to a large national $\mathrm{PH}$ expert referral centre. In each case, the assessment and therapeutic approach undertaken is described in the context of the new ECS/ERS guidelines. The routine diagnostic work-up of suspected idiopathic pulmonary arterial hypertension (PAH) and recommended treatments for patients with functional class II, III and IV disease is emphasised. Familial screening and management of heritable PAH is discussed. Appropriate investigation and therapeutic strategies for patients with chronic thromboembolic disease and $\mathrm{PH}$ that is associated with congenital heart disease, pulmonary veno-occlusive disease and systemic sclerosis are also highlighted.

$\mathbf{T}$ he term pulmonary hypertension (PH) describes a group of devastating and lifelimiting diseases, defined by a mean pulmonary artery pressure $\left(\bar{P}_{\mathrm{pa}}\right) \geqslant 25 \mathrm{mmHg}$ at rest [1-8]. PH remains poorly characterised as it is a rare disorder and because there is an incomplete understanding of the diverse underlying pathogenic conditions and mechanisms. Furthermore, effective treatment approaches available to clinicians have traditionally been limited. However, the past decade has witnessed a significant increase in our knowledge base, leading to novel medical, surgical and supportive therapeutic options for patients. In addition, international collaborative efforts have directly led to the development of regularly updated proceedings and guidelines $[1,2,9]$. The recent publication of the joint European Society of Cardiology (ESC) and European Respiratory Society (ERS) guidelines is a major event in our community and it thus appeared timely to comment on these guidelines with real-life cases managed according to this approach [1, 2]. Indeed, it is essential to implement these guidelines in day-to-day care of this fragile patient population $[4,10]$. This article describes a number of real-life clinical cases and focuses on the management approaches employed at a large national pulmonary vascular disease referral centre. The level of evidence and the strength of recommendation of particular treatment options are weighed and graded according to pre-defined scales, as presented in tables 1 and 2 .

\section{CASE 1: DIAGNOSTIC WORK-UP IN IDIOPATHIC PULMONARY ARTERIAL HYPERTENSION \\ Case report}

A 30-yr-old female presented with progressive dyspnoea associated with intermittent episodes of dizziness. She was a nonsmoker and had no history of venous thromboembolism, Raynaud's phenomenon or exposure to anorexigens. Family history was noncontributory. At initial assessment after referral to a $\mathrm{PH}$ expert centre she was deemed functional class III. Physical examination was remarkable only for a loud second heart sound over the pulmonic valve. There was no clinical to be in World Health Organization (WHO)

\section{AFFILIATIONS}

*Univ Paris-Sud, Faculté de médecine, Kremlin-Bicêtre, ${ }^{\#}$ AP-HP, Centre National de Référence de l'Hypertension Pulmonaire Sévère, Service de Pneumologie et Réanimation Respiratoire, Hôpital Antoine Béclère, Clamart, and

"INSERM U999 Hypertension Artérielle Pulmonaire,

Physiopathologie et Innovation Thérapeutique, Clamart, Le Plessis Robinson, France.

${ }^{+}$D. Montani and D.S. O'Callaghan contributed equally to this manuscript.

CORRESPONDENCE

D. Montani

Service de Pneumologie,

Hôpital Antoine Béclère,

Assistance Publique Hôpitaux de Paris

Université Paris-Sud 11

157 rue de la Porte de Trivaux 92140 Clamart

France

E-mail: david.montani@abc.aphp.fr

Received:

Oct 082009

Accepted after revision:

Oct 132009

PROVENANCE

Publication of this peer-reviewed article was supported by GlaxoSmithKline, UK (principal sponsor, European Respiratory Review issue 114).

European Respiratory Review Print ISSN 0905-9180

Online ISSN 1600-0617 


\begin{tabular}{|c|c|}
\hline & Definition \\
\hline Class I & $\begin{array}{l}\text { Evidence and/or general agreement that a given treatment } \\
\text { or procedure is beneficial, useful, effective. }\end{array}$ \\
\hline Class II & $\begin{array}{l}\text { Conflicting evidence and/or a divergence of opinion } \\
\text { about the usefulness/efficacy of the given } \\
\text { treatment or procedure. }\end{array}$ \\
\hline Class IIa & Weight of evidence/opinion is in favour of usefulness/efficacy. \\
\hline Class IIb & Usefulness/efficacy is less well established by evidence/opinion. \\
\hline Class III & $\begin{array}{l}\text { Evidence or general agreement that the given treatment or } \\
\text { procedure is not useful/effective, and in some cases } \\
\text { may be harmful. }\end{array}$ \\
\hline
\end{tabular}

Reproduced from [1] with permission from the publisher.

evidence of connective tissue disease (CTD). Transthoracic echocardiography revealed dilated right heart chambers, moderate impairment of right ventricular contractility and a systolic $P$ pa estimated to be $70 \mathrm{mmHg}$. Her 6-min walk distance (6MWD) was $310 \mathrm{~m}$. Pulmonary function tests (PFTs) and arterial blood gas analysis were within normal limits. The only abnormality observed on high-resolution computed tomography (HRCT) was mild dilatation of the pulmonary arteries. Ventilation/ perfusion lung scintigraphy demonstrated some subsegmental mismatched defects but findings were not consistent with a diagnosis of chronic thromboembolic PH (CTEPH). Testing for infection with hepatitis $B$, hepatitis $C$ and HIV was negative and liver function tests were normal. Portal hypertension was excluded by abdominal ultrasound. The patient proceeded to diagnostic right heart catheterisation (RHC), which confirmed severe pre-capillary $\mathrm{PH}\left(\bar{P}_{\mathrm{pa}} 55 \mathrm{mmHg}\right.$, pulmonary capillary wedge pressure $(P \mathrm{pcw}) \quad 8 \mathrm{mmHg}$, cardiac index (CI) $2.88 \mathrm{~L} \cdot \mathrm{min}^{-1} \cdot \mathrm{m}^{-2}$ and pulmonary vascular resistance (PVR) $694 \mathrm{dyn} \cdot \mathrm{s} \cdot \mathrm{cm}^{-5}$ ). Acute vasodilator testing with inhaled nitric oxide was negative. As no identifiable underlying cause was revealed by the various investigations performed for the workup of $\mathrm{PH}$ in this patient, a diagnosis of idiopathic pulmonary arterial hypertension (PAH) was established and endothelin receptor antagonist therapy was instituted. Oral anticoagulation for a target international normalised ratio (INR) of 2-3 was initiated, and the patient was advised on effective contraception measures as well as avoidance of excessive physical activity. A clinical and haemodynamic re-evaluation after 4 months was scheduled.

\section{TABLE 2 ESC/ERS guidelines: levels of evidence}

\begin{tabular}{|c|c|}
\hline Level of evidence $A$ & 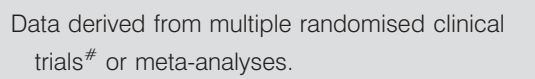 \\
\hline Level of evidence B & $\begin{array}{l}\text { Data derived from multiple randomised clinical } \\
\text { trials }{ }^{\#} \text { or large nonrandomised studies. }\end{array}$ \\
\hline Level of evidence C & $\begin{array}{l}\text { Consensus of opinion of the experts and/or small } \\
\text { studies, retrospective studies, registries. }\end{array}$ \\
\hline
\end{tabular}

\#: or large accuracy or outcome trial(s) in the case of diagnostic tests or strategies. Reproduced from [1] with permission from the publisher.

\section{Commentary: relevance to ESC/ERS guidelines}

$\mathrm{PH}$ has been defined as an increase in $\bar{P}_{\text {pa }} \geqslant 25 \mathrm{mmHg}$ at rest, as assessed by RHC.

The definition of $\mathrm{PH}$ on exercise as a $\bar{P}$ pa $\geqslant 30 \mathrm{mmHg}$ is not supported by published data and healthy individuals can reach much higher values. Thus no definition for $\mathrm{PH}$ on exercise as assessed by RHC can be provided at the present time.

According to various combinations of values of $P$ pcw, PVR and cardiac output (CO), different haemodynamic definitions of $\mathrm{PH}$ are shown in table 3.

To avoid possible confusion among the terms $\mathrm{PH}$ and $\mathrm{PAH}$, the specific definitions have been included in table 4 .

Compared with the previous version of the clinical classification, a number of changes have been made (table 5). 1) In group 1, corresponding to $\mathrm{PAH}$, the term familial $\mathrm{PAH}$ has been replaced by heritable $\mathrm{PAH}$ that includes clinically sporadic idiopathic $\mathrm{PAH}$ with germline mutations and clinical familial cases with or without identified germline mutations. 2) Associated PAH includes conditions that can have a similar clinical presentation to that seen in idiopathic PAH with identical histological findings, and accounts for approximately half of all PAH patients. Schistosomiasis and chronic haemolytic anaemia have been now included among the associated PAH forms. 3) A group 1' has been created, which includes pulmonary veno-occlusive disease (PVOD) and pulmonary capillary haemangiomatosis ( $\mathrm{PCH})$, as these disorders share some characteristics with idiopathic PAH but also demonstrate a number of differences.

\begin{tabular}{|c|c|c|}
\hline Definition & Characteristics & Clinical group(s) \\
\hline PH & $\bar{P} \mathrm{pa} \geqslant 25 \mathrm{mmHg}$ & All \\
\hline \multirow[t]{3}{*}{ Pre-capillary PH } & $\bar{P} \mathrm{pa} \geqslant 25 \mathrm{mmHg}$ & $\begin{array}{l}\text { 1. Pulmonary arterial } \\
\text { hypertension }\end{array}$ \\
\hline & $P$ pcw $\leqslant 15 \mathrm{mmHg}$ & 3. $\mathrm{PH}$ due to lung diseases \\
\hline & $\begin{array}{l}\text { CO normal or } \\
\text { reduced }^{+}\end{array}$ & $\begin{array}{l}\text { 4. Chronic thromboembolic } \mathrm{PH} \\
\text { 5. } \mathrm{PH} \text { with unclear and/or } \\
\text { multifactorial mechanisms }\end{array}$ \\
\hline \multirow[t]{3}{*}{ Post-capillary PH } & $\bar{P}_{\mathrm{pa}} \geqslant 25 \mathrm{mmHg}$ & 2. $\mathrm{PH}$ due to left heart disease \\
\hline & Ppcw $>15 \mathrm{mmHg}$ & \\
\hline & $\begin{array}{l}\text { CO normal or } \\
\text { reduced }^{+}\end{array}$ & \\
\hline Passive & $\mathrm{TPG} \leqslant 12 \mathrm{mmHg}$ & \\
\hline $\begin{array}{c}\text { Reactive (out of } \\
\text { proportion) }\end{array}$ & $\mathrm{TPG}>12 \mathrm{mmHg}$ & \\
\hline
\end{tabular}

$\bar{P}_{\text {pa: }}$ mean pulmonary arterial pressure; $P$ pcw: pulmonary capillary wedge pressure; CO: cardiac output; TPG: transpulmonary pressure gradient $\left(\bar{P}_{\text {pa-}}-\bar{P}_{\text {pcw }}\right) .{ }^{*}$ : all values measured at rest; " : according to table 5 ; ${ }^{+}$: high CO can be present in cases of hyperkinetic conditions such as systemic-topulmonary shunts (only in the pulmonary circulation), anaemia, hyperthyroidism, etc. Reproduced from [1] with permission from the publisher. 




PH: pulmonary hypertension; $\bar{P}$ pa: mean pulmonary arterial pressure; $\mathrm{PAH}$ pulmonary arterial hypertension. Reproduced from [1] with permission from the publisher

The evaluation process of a patient with suspected $\mathrm{PH}$ requires a series of investigations intended to confirm the diagnosis, clarify the clinical group of $\mathrm{PH}$ and the specific aetiology within the PAH group, and evaluate the functional and haemodynamic impairment.

Since PAH, and particularly idiopathic $\mathrm{PAH}$, is a diagnosis of exclusion, a diagnostic algorithm may be useful as a starting point in any case of suspected $\mathrm{PH}$ (fig. 1), as follows:

1) The symptoms of PAH are nonspecific and include breathlessness, fatigue, weakness, angina, syncope and abdominal distension. In $90 \%$ of patients with idiopathic $\mathrm{PAH}$ the chest radiograph is abnormal at the time of diagnosis. The ECG may provide suggestive or supportive evidence of $\mathrm{PH}$ by demonstrating right ventricular hypertrophy and strain, and right atrial dilatation.

2) Transthoracic echocardiography provides several variables that correlate with right heart haemodynamics, including $P$ pa, and should always be performed in the case of suspected $\mathrm{PH}$. The estimation of $P$ pa during echocardiography is based on the peak velocity of the jet of tricuspid regurgitation. Other echocardiographic variables that might reinforce suspicion of $\mathrm{PH}$ include an increased velocity of pulmonic valve regurgitation, short acceleration time of right ventricular ejection into the pulmonary artery, increased dimensions of right heart chambers, abnormal shape and function of the interventricular septum, increased right ventricular wall thickness, and dilatation of the main pulmonary artery.

3) PFTs and arterial blood gases will identify the contribution of underlying airway or parenchymal lung disease. Patients with PAH usually have decreased diffusion capacity for carbon monoxide $(\mathrm{DL}, \mathrm{CO})$ and mild to moderate reduction of lung volumes.

4) The ventilation/perfusion lung scan should be performed in patients with $\mathrm{PH}$ to look for potentially treatable CTEPH. The ventilation/perfusion scan remains the screening method of choice for CTEPH and a normal or low probability effectively excludes CTEPH with a sensitivity $>90 \%$ and a specificity $>94 \%$.

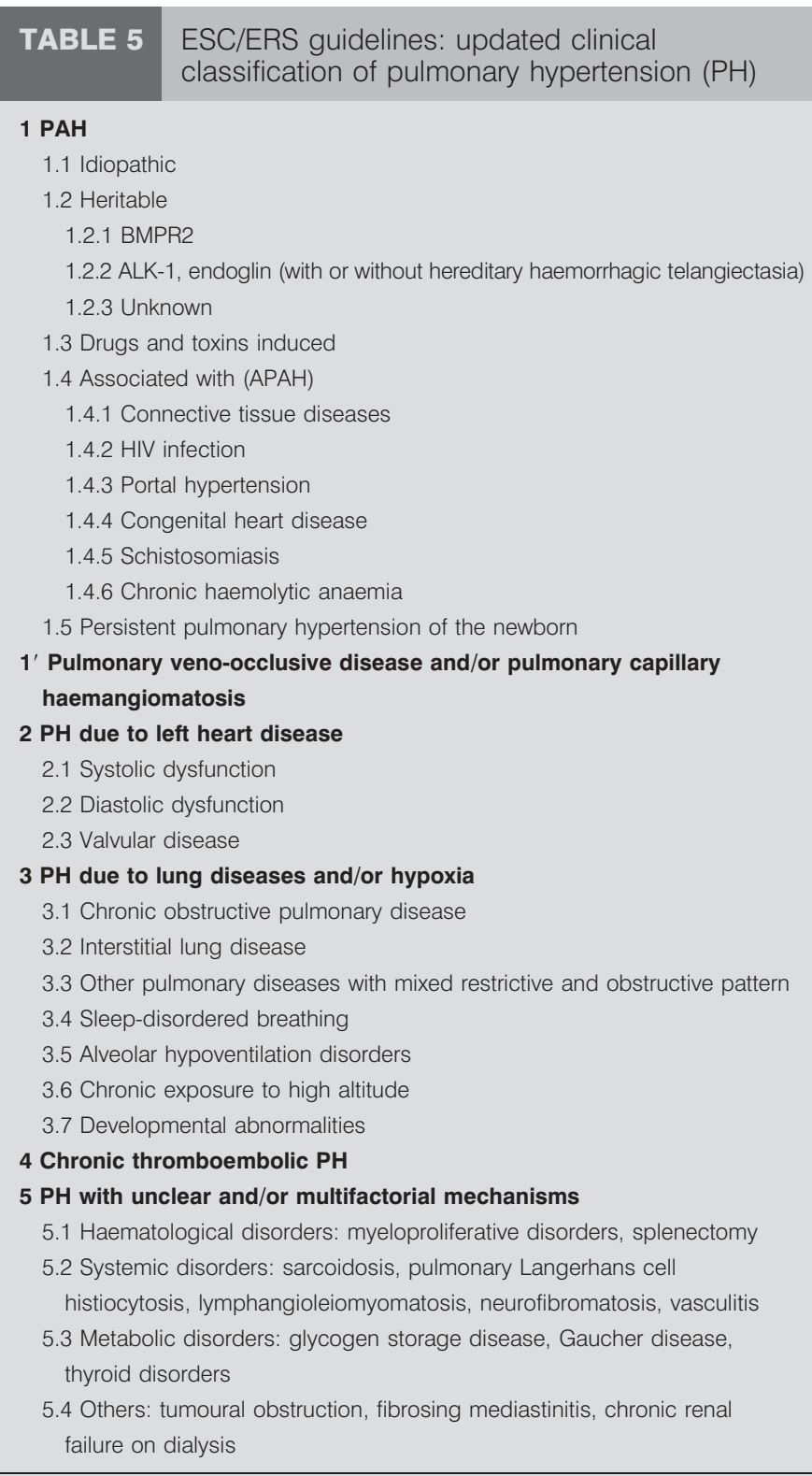

$\mathrm{PAH}$ : pulmonary arterial hypertension; BMPR2: bone morphogenetic protein receptor, type 2; ALK-1: activin receptor-like kinase 1; APAH: associated pulmonary arterial hypertension. Reproduced from [11] with permission from the publisher.

5) HRCT facilitates the diagnosis of interstitial lung disease and emphysema and may be very helpful where there is a suspicion of PVOD or PCH.

6) Liver cirrhosis and/or portal hypertension can be reliably excluded by the use of abdominal ultrasound.

7) Routine biochemistry, haematology and thyroid function tests are required in all patients, as well as a number of other essential blood tests. Serological testing is important to detect underlying CTD, HIV and hepatitis.

RHC is required to confirm the diagnosis of PAH, to assess the severity of the haemodynamic impairment and to test the 


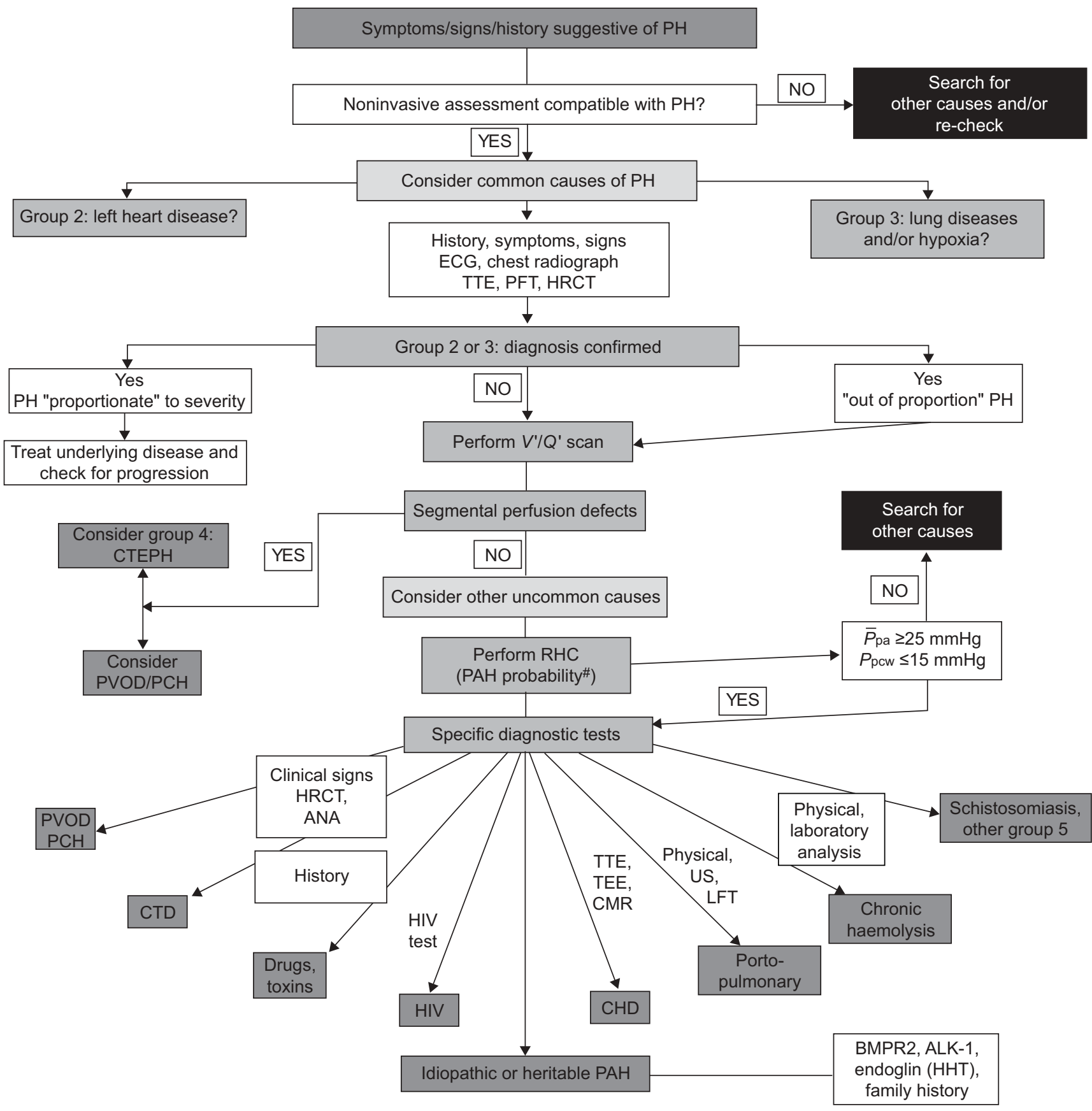

FIGURE 1. Diagnostic algorithm. ALK-1: activin-receptor-like kinase; ANA: antinuclear antibodies; BMPR2: bone morphogenetic protein receptor 2; CHD: congenital heart disease; CMR: cardiac magnetic resonance; CTD: connective tissue disease; CTEPH: chronic thromboembolic pulmonary hypertension; HHT: hereditary haemorrhagic telangiectasia; HRCT: high-resolution computed tomography; LFT: liver function tests; $\bar{P}$ pa: mean pulmonary arterial pressure; PAH: pulmonary arterial hypertension; PCH: pulmonary capillary haemangiomatosis; Ppcw: pulmonary capillary wedge pressure; PFT: pulmonary function test; PH: pulmonary hypertension; PVOD: pulmonary venoocclusive disease; RHC: right heart catheterisation; TEE: trans-oesophageal echocardiography; TTE: transthoracic echocardiography; US: ultrasonography; $V^{\prime} / Q^{\prime}$ scan: ventilation/perfusion lung scan. ${ }^{*}$ : refer also to table 9 . Reproduced from [1] with permission from the publisher

vasoreactivity of the pulmonary circulation. The following variables must be recorded during RHC. 1) Ppa (systolic, diastolic and mean), right atrial pressure, $P$ pcw and right ventricular pressure. $\mathrm{CO}$ must be measured in triplicate, preferably by thermodilution or by the Fick method. 2) Adequate recording of $P \mathrm{pcw}$ is required for the differential diagnosis of $\mathrm{PH}$ due to left heart disease.
Special awareness should be directed towards patients with associated conditions and/or risk factors for development of $\mathrm{PAH}$, such as family history, CTD, congenital heart disease (CHD), HIV infection, portal hypertension, haemolytic anaemia or a history of intake of drugs and toxins known to induce $\mathrm{PAH}$. If noninvasive assessment is compatible with $\mathrm{PH}$, clinical history, symptoms, signs, ECG, chest radiograph, transthoracic 


\section{TABLE 6 ESC/ERS guidelines: functional classification of pulmonary hypertension modified after the New York Heart Association functional classification according to the World Health Organization}

Class I Patients with pulmonary hypertension but without resulting limitation of physical activity. Ordinary physical activity does not cause undue dyspnoea or fatigue, chest pain, or near syncope.

Class II Patients with pulmonary hypertension resulting in slight limitation of physical activity. They are comfortable at rest. Ordinary physical activity causes undue dyspnoea or fatigue, chest pain, or near syncope.

Class III Patients with pulmonary hypertension resulting in marked limitation of physical activity. They are comfortable at rest. Less than ordinary activity causes undue dyspnoea or fatigue, chest pain, or near syncope.

Class IV Patients with pulmonary hypertension with inability to carry out any physical activity without symptoms. These patients manifest signs of right heart failure. Dyspnoea and/or fatigue may even be present at rest. Discomfort is increased by any physical activity.

Reproduced from [12] with permission from the publishers.

echocardiogram, PFTs and HRCT of the chest are requested to identify the presence of group 2 left heart disease or group 3 lung diseases. If a ventilation/perfusion scan shows multiple segmental perfusion defects, a diagnosis of group 4 CTEPH should be suspected. The final diagnosis of CTEPH (and the assessment of suitability for pulmonary endarterectomy) will require computed tomography (CT) angiography, RHC and selective pulmonary angiography.

TABLE $7 \begin{aligned} & \text { ESC/ERS guidelines: recommendations for } \\ & \text { pulmonary arterial hypertension (PAH) associated } \\ & \text { with connective tissue disease (CTD) }\end{aligned}$
$\begin{aligned} & \text { Class }{ }^{\#} \\ & \text { Statement }\end{aligned}$
$\begin{aligned} & \text { In pevel } \\ & \text { treatients with PAH associated with CTD the same }\end{aligned}$
PAH is recommended
Echocardiographic screening for the detection of
PH is recommended in symptomatic patients with
scleroderma spectrum of diseases
Echocardiographic screening for the detection of
PH is recommended in symptomatic patients with
all other CTDs
RHC is indicated in all cases of suspected PAH
associated with CTD, in particular if specific drug
therapy is considered
Oral anticoagulation should be considered on an
individual basis
Echocardiographic screening for the detection of
PH may be considered in asymptomatic patients with
the scleroderma spectrum of disease

$\mathrm{PH}$ : pulmonary hypertension; RHC: right heart catheterisation. \#: class of recommendation; $"$ : level of evidence. Reproduced from [1] with permission from the publishers.
The clinical assessment of the patient has a pivotal role in the choice of the initial treatment, the evaluation of the response to therapy, and the possible escalation of therapy if needed. Despite large interobserver variation in the measurement, $\mathrm{WHO}$ functional class (table 6) remains a powerful predictor of survival. In untreated patients with idiopathic or heritable $\mathrm{PAH}$, historical data showed a median survival of 6 months for WHO functional class IV, 2.5 yrs for WHO functional class III, and 6 yrs for WHO functional classes I and II.

\section{CASE 2: SYSTEMIC SCLEROSIS-ASSOCIATED PAH}

\section{Case report}

A 37-yr-old female with limited systemic sclerosis (LSSc) was referred by her rheumatologist for assessment of increasing exercise intolerance associated with effort-induced chest discomfort and dizziness. Physical examination was remarkable for an accentuated pulmonic component of the second heart sound, a parasternal heave and mucocutaneous features consistent with LSSc. Auscultation of the lungs was unremarkable and there was no clinical evidence of right heart failure. Transthoracic echocardiography revealed a left ventricle compromised by markedly dilated right heart chambers with associated paradoxical motion of the interventricular septum and a 1-cm circumferential noncompressive pericardial effusion. Spirometry and lung volume measurements were normal and there was no evidence of interstitial lung disease on HRCT of the chest. RHC confirmed severe pre-capillary $\mathrm{PH}\left(\bar{P}_{\mathrm{pa}}\right.$

\begin{tabular}{|c|c|c|c|}
\hline TABLE 8 & \multicolumn{3}{|c|}{$\begin{array}{l}\text { ESC/ERS guidelines: arbitrary criteria for } \\
\text { estimating the presence of pulmonary } \\
\text { hypertension }(\mathrm{PH}) \text { based on tricuspid regurgitation } \\
\text { peak velocity and Doppler-calculated systolic } \\
\text { pulmonary arterial pressure ( } \mathrm{Ppa} \text { ) at rest (assuming } \\
\text { a normal right atrial pressure of } 5 \mathrm{mmHg} \text { ) and on } \\
\text { additional echocardiographic variables suggestive } \\
\text { of } \mathrm{PH}\end{array}$} \\
\hline Criteria & & Class & Level $^{*}$ \\
\hline \multicolumn{4}{|c|}{ Echocardiographic diagnosis: $\mathrm{PH}$ unlikely } \\
\hline \multicolumn{2}{|c|}{$\begin{array}{l}\text { Tricuspid regurgitation velocity } \leqslant 2.8 \mathrm{~m} \cdot \mathrm{s}^{-1} \text {, systolic } P \text { pa } \\
\leqslant 36 \mathrm{mmHg} \text { and no additional echocardiographic variables } \\
\text { suggestive of } \mathrm{PH}\end{array}$} & । & B \\
\hline \multicolumn{4}{|c|}{ Echocardiographic diagnosis: $\mathrm{PH}$ possible } \\
\hline \multicolumn{2}{|c|}{$\begin{array}{l}\text { Tricuspid regurgitation velocity } \leqslant 2.8 \mathrm{~m} \cdot \mathrm{s}^{-1} \text {, systolic } P \text { pa } \\
\leqslant 36 \mathrm{mmHg} \text {, but presence of additional } \\
\text { echocardiographic variables suggestive of } \mathrm{PH}\end{array}$} & Ila & C \\
\hline \multicolumn{2}{|c|}{$\begin{array}{l}\text { Tricuspid regurgitation velocity } 2.9-3.4 \mathrm{~m} \cdot \mathrm{s}^{-1} \text {, systolic } \\
\text { Ppa } 37-50 \mathrm{mmHg} \text { with/without additional } \\
\text { echocardiographic variables suggestive of } \mathrm{PH}\end{array}$} & Ila & C \\
\hline \multicolumn{4}{|c|}{ Echocardiographic diagnosis: PH likely } \\
\hline \multicolumn{2}{|c|}{$\begin{array}{l}\text { Tricuspid regurgitation velocity }>3.4 \mathrm{~m} \cdot \mathrm{s}^{-1} \text {, systolic } P \text { pa } \\
>50 \mathrm{mmHg} \text {, with/without additional echocardiographic } \\
\text { variables suggestive of } \mathrm{PH}\end{array}$} & I & B \\
\hline \multicolumn{2}{|c|}{$\begin{array}{l}\text { Exercise Doppler echocardiography is not recommended } \\
\text { for screening of } \mathrm{PH}\end{array}$} & III & $\mathrm{C}$ \\
\hline
\end{tabular}




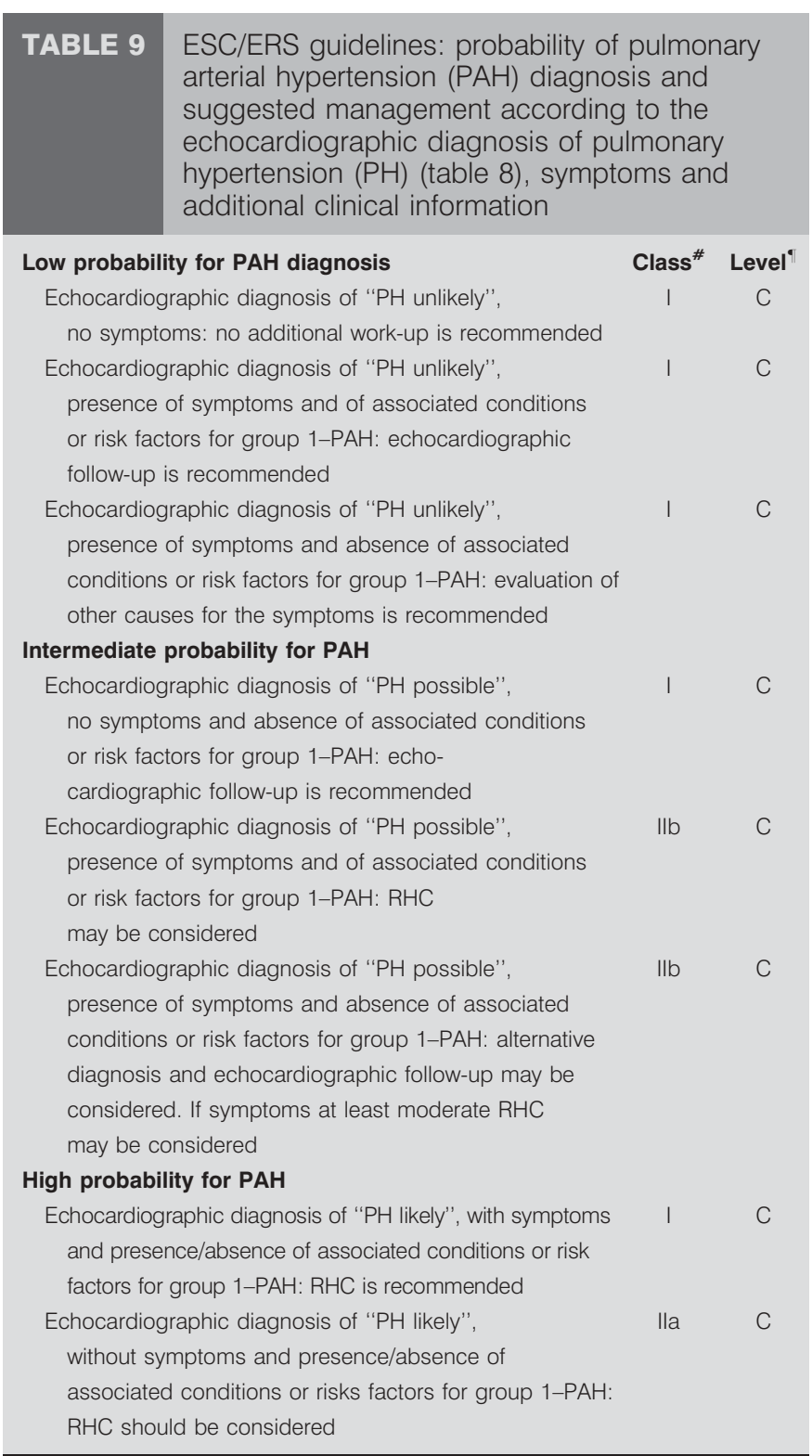

RHC: right heart catheterisation. ${ }^{\#}$ : class of recommendation; ": level of evidence. Reproduced from [1] with permission from the publisher.

$73 \mathrm{mmHg}$, PVR 1,950 dyn $\cdot \mathrm{s}^{-\mathrm{cm}^{-5}}$ and $P$ pcw $10 \mathrm{mmHg}$ ) with evidence of volume overload (right atrial pressure $20 \mathrm{mmHg}$ ) and no acute vasodilator response to inhaled nitric oxide. The patient was deemed to be in WHO functional class III and was commenced on treatment with oral endothelin receptor antagonist. In addition, diuretics and anticoagulation with a target INR of 2.0-3.0 were initiated. Monthly surveillance of liver transaminases was advised and effective contraceptive measures suggested. At re-evaluation after 4 months of therapy, the patient reported a symptomatic improvement and her 6MWD increased to $365 \mathrm{~m}$ from a baseline of $250 \mathrm{~m}$. There was also a modest improvement in the pulmonary haemodynamic profile at repeat RHC ( $\bar{P}_{\text {pa }} 65 \mathrm{mmHg}$, PVR $1,800 \mathrm{dyn} \cdot \mathrm{s} \cdot \mathrm{cm}^{-5}$ and right atrial pressure $15 \mathrm{mmHg}$ ).
TABLE 10 Case 3: invasive pulmonary haemodynamics

Baseline

After $500 \mathrm{~mL}$ fluid challenge

$\begin{array}{lcc}\text { Pra } \mathbf{~ m m H g} & 7 & 13 \\ \text { P pa mmHg } & 26 & 33 \\ \text { Ppcw } \mathbf{~ m m H g} & 8 & 21 \\ \text { CO L. } \mathbf{m i n}^{-1} & 4.82 & 5.43 \\ \text { Cl L } \cdot \mathbf{m i n}^{-1} \cdot \mathbf{m}^{-2} & 2.71 & 3.02 \\ \text { PVR } \text { dyn } \cdot \mathbf{s} \cdot \mathbf{c m}^{-5} & 299 & 177\end{array}$

Pra: right atrial pressure; $\bar{P}$ pa: mean pulmonary arterial pressure; $P_{p c w}$ pulmonary capillary wedge pressure; $\mathrm{CO}$ : cardiac output; $\mathrm{Cl}$ : cardiac index PVR: pulmonary vascular resistance.

\section{Commentary: relevance to ESC/ERS guidelines}

$\mathrm{PAH}$ is a well-known complication of CTD such as systemic sclerosis, systemic lupus erythematosus, mixed CTD and, to a lesser extent, rheumatoid arthritis, dermatomyositis and Sjögren's syndrome. PAH associated with CTD is the second most prevalent type of PAH after idiopathic PAH.

Systemic sclerosis, particularly in its limited variant, represents the main CTD associated with PAH. The prevalence of haemodynamically proven $\mathrm{PAH}$ in large cohorts of patients with systemic sclerosis is between $7 \%$ and $12 \%$. Compared with idiopathic $\mathrm{PAH}$, patients with $\mathrm{CTD}$ and $\mathrm{PAH}$ are mainly females (female to male ratio 4:1), are older (mean age at diagnosis $66 \mathrm{yrs}$ ), may present concomitant disorders (pulmonary fibrosis and left heart disease) and have shorter survival.

Echocardiographic screening for the detection of $\mathrm{PH}$ has been recommended annually in asymptomatic patients with the scleroderma spectrum of diseases but only in the presence of symptoms in other CTD (table 7).

The reliability of several tricuspid regurgitation velocity cut-off values, using RHC as reference, has been assessed in two large screening studies. A trial evaluating the reliability of prospective screening of patients with scleroderma, based on tricuspid regurgitation velocity $>2.5 \mathrm{~m} \cdot \mathrm{s}^{-1}$ in symptomatic patients or $>3.0 \mathrm{~m} \cdot \mathrm{s}^{-1}$ irrespective of symptoms, found that $45 \%$ of cases of echocardiographic diagnoses of $\mathrm{PH}$ were falsely positive. Another trial selected a tricuspid regurgitation pressure gradient $>40 \mathrm{mmHg}$ (tricuspid regurgitation velocity $>3.2 \mathrm{~m} \cdot \mathrm{s}^{-1}$ ) with an assumed right atrial pressure of $10 \mathrm{mmHg}$ as the cut-off value for diagnosis of $\mathrm{PH}$. Those criteria were recently prospectively applied in systemic sclerosis patients.

In tables 8 and 9, the ESC/ERS task force suggests arbitrary criteria for detecting the presence of $\mathrm{PH}$ based on tricuspid regurgitation peak velocity and Doppler-calculated systolic $P$ pa at rest (assuming a normal right atrial pressure of $5 \mathrm{mmHg}$ ) and additional echocardiographic variables suggestive of $\mathrm{PH}$.

\section{CASE 3: SYSTEMIC SCLEROSIS-ASSOCIATED POST- CAPILLARY PH}

\section{Case report}

A 67-yr-old female in whom LSSc was diagnosed $11 \mathrm{yrs}$ previously was referred for assessment of $\mathrm{PH}$. She reported worsening dyspnoea on exertion over the preceding several 


\begin{tabular}{l} 
TABLE $11 \quad \begin{array}{l}\text { ESC/ERS guidelines: factors favouring diagnosis } \\
\text { of left ventricular diastolic dysfunction in the } \\
\text { presence of pulmonary hypertension as } \\
\text { assessed by Doppler echocardiography }\end{array}$ \\
Clinical features \\
Age $>65$ yrs \\
Elevated systolic blood pressure \\
Elevated pulse pressure \\
Obesity, metabolic syndrome \\
Hypertension \\
Coronary artery disease \\
Diabetes mellitus \\
Atrial fibrillation \\
Echocardiography \\
Left atrial enlargement \\
Concentric remodelling of the LV (relative wall thickness >0.45) \\
LV hypertrophy \\
Presence of echocardiographic indicators of elevated LV filling \\
pressure [13, 14] \\
Interim evaluation (after echocardiography) \\
Symptomatic response to diuretics \\
Exaggerated increase in systolic blood pressure with exercise \\
Re-evaluation of chest radiograph consistent with heart failure [14] \\
\hline
\end{tabular}

LV: left ventricle. Modified from [15] with permission from the publisher.

months associated with intermittent episodes of chest discomfort and mild leg swelling, in addition to severe Raynaud's phenomenon and gastro-oesophageal reflux symptoms. Physical

\begin{tabular}{|c|c|c|c|}
\hline TABLE 12 & \multicolumn{3}{|c|}{$\begin{array}{l}\text { ESC/ERS guidelines: recommendations for } \\
\text { pulmonary hypertension }(\mathrm{PH}) \text { due to left heart } \\
\text { disease }\end{array}$} \\
\hline \multicolumn{2}{|l|}{ Statement } & Class $^{\#}$ & Level ${ }^{\circ}$ \\
\hline \multicolumn{2}{|c|}{$\begin{array}{l}\text { The optimal treatment of the underlying left heart } \\
\text { disease is recommended in patients with PH due to } \\
\text { left heart disease }\end{array}$} & I & C \\
\hline \multicolumn{2}{|c|}{$\begin{array}{l}\text { Patients with "out of proportion" PH due to left } \\
\text { heart disease (table } 3 \text { ) should be enrolled in } \\
\text { RCTs targeting PH specific drugs }\end{array}$} & Ila & C \\
\hline \multicolumn{2}{|c|}{$\begin{array}{l}\text { Increased left-sided filling pressures may be } \\
\text { estimated by Doppler echocardiography }\end{array}$} & $11 \mathrm{~b}$ & C \\
\hline \multicolumn{2}{|c|}{$\begin{array}{l}\text { Invasive measurements of } P \text { pcw or } L V \text { end-diastolic } \\
\text { pressure may be required to confirm the diagnosis } \\
\text { of } \mathrm{PH} \text { due to left heart disease }\end{array}$} & $\mathrm{llb}$ & C \\
\hline \multicolumn{2}{|c|}{$\begin{array}{l}\text { RHC may be considered in patients with } \\
\text { echocardiographic signs suggesting severe } \\
\text { PH in patients with left heart disease }\end{array}$} & $\| \mathrm{lb}$ & C \\
\hline \multicolumn{2}{|c|}{$\begin{array}{l}\text { The use of PAH specific drug therapy is not } \\
\text { recommended in patients with PH due to } \\
\text { left heart disease }\end{array}$} & III & C \\
\hline
\end{tabular}

RCT: randomised controlled trial; $P$ pcw: pulmonary capillary wedge pressure; LV: left ventricular; RHC: right heart catheterisation; $\mathrm{PAH}$ : pulmonary arterial hypertension. " : class of recommendation; ": level of evidence. Reproduced from [1] with permission from the publisher. examination was remarkable for severe calcinosis involving both hands and extensive telangiectasia. She was normotensive and there was no clinical evidence of cardiac failure. PFTs revealed normal spirometry and lung volume measurements and a DL,CO of $60 \%$ predicted. She was referred to an expert centre for evaluation of suspected PAH as transthoracic echocardiography demonstrated enlarged right heart chambers and an estimated systolic P pa of $50 \mathrm{mmHg}$ with normal left ventricular function, mild left atrial enlargement, normal valvular structure and a normal pericardium. At review, she was in WHO functional class III with a 6MWD of $320 \mathrm{~m}$. HRCT showed mild bibasal interstitial infiltrates. Liver function tests, blood gas analysis, lung scintigraphy, abdominal ultrasound and polysomnography were normal and HIV test was negative. RHC was performed and confirmed mild PH ( $\bar{P}_{\text {pa }} 26 \mathrm{mmHg}$ ) with normal P pcw (table 10). Because of the strong suspicion of underlying left heart disease, a fluid challenge (500 mL saline over $10 \mathrm{~min}$ ) was administered and repeat measurements of pulmonary haemodynamics were made, revealing a profile consistent with post-capillary $\mathrm{PH}$ in the context of diastolic left heart disease associated with scleroderma (table 10).

\section{Commentary: relevance to ESC/ERS guidelines}

The diagnostic approach to $\mathrm{PH}$ due to left heart disease is similar to that for $\mathrm{PAH}$, doppler echocardiography being the best tool for screening purposes.

Left ventricle diastolic dysfunction should be suspected in the presence of a dilated left atrium, atrial fibrillation, characteristic changes in mitral flow profile, pulmonary venous flow profile, and mitral annulus tissue Doppler signals and left ventricle hypertrophy. Characteristic clinical and echocardiographic features of $\mathrm{PH}$ associated with left ventricle diastolic dysfunction are listed in table 11.

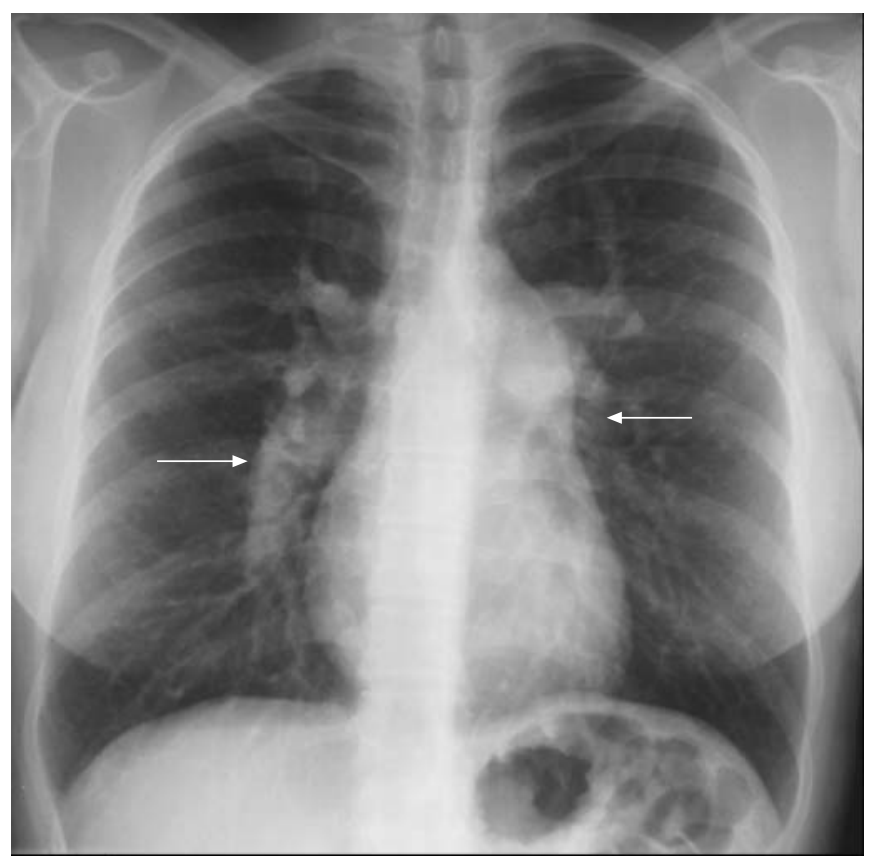

FIGURE 2. Chest radiograph showing markedly dilated pulmonary arteries (arrows) 


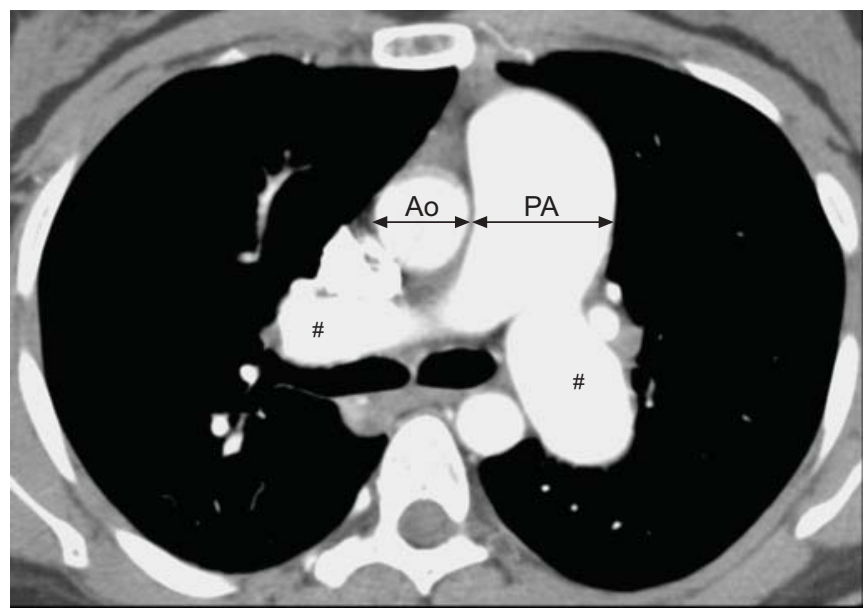

FIGURE 3. Contrast-enhanced computed tomography of the chest of a patient with pulmonary arterial hypertension associated with congenital heart disease (large atrial septal defect). Massive dilatation of the pulmonary arterial trunk and branches $(\#)$. The ratio of the diameter of aorta $(\mathrm{Ao})$ to the diameter of main pulmonary artery $(\mathrm{PA})$ is $>1.5$

Adequate recording of $P$ pcw is required for the differential diagnosis of $\mathrm{PH}$ due to left heart disease. In rare cases, left heart catheterisation may be required for direct assessment of left ventricular end-diastolic pressure.

A $P$ pcw $>15 \mathrm{mmHg}$ excludes the diagnosis of pre-capillary PAH.

One of the most challenging differential diagnoses of PAH is heart failure with normal left ventricular ejection fraction and diastolic dysfunction. In this population, $P$ pcw may be mildly elevated or at the higher end of the normal range at rest. $P_{\mathrm{pcw}}$ and left ventricular end-diastolic pressure can be "pseudonormal", especially when patients have been treated with diuretics. In this setting, exercise haemodynamic volume challenge has been proposed to identify left ventricular dysfunction, but these diagnostic tools require further standardisation.

An elevated transpulmonary gradient $\left(\bar{P}_{\mathrm{pa}}-\bar{P}_{\mathrm{pcw}}\right)>12 \mathrm{mmHg}$ is suggestive of intrinsic changes in the pulmonary circulation overriding the passive increase in $P$ pcw.

Recommendations for $\mathrm{PH}$ due to left heart disease are summarised in table 12 .

\section{CASE 4: PAH AND CONGENITAL HEART DISEASE Case report}

A 24-yr-old female was referred for assessment of suspected PH. Except for mild asthma treated with a short-acting $\beta_{2}$-adrenergic agonist, she had no significant personal or familial medical history and denied illicit drug or appetite suppressant intake. 2 months before admission, a chest radiograph was performed for tuberculosis contact screening and revealed markedly dilated pulmonary arteries (fig. 2). She reported mild dyspnoea on exertion (WHO functional class II) over the preceding several months. Physical examination revealed an accentuated second heart sound over the pulmonic valve but was otherwise normal. ECG showed right ventricular hypertrophy and an incomplete
TABLE 13 ESC/ERS guidelines: clinical classification of congenital, systemic-to-pulmonary shunts associated with pulmonary arterial hypertension (PAH)

\section{A. Eisenmenger's syndrome}

Eisenmenger's syndrome includes all systemic-to-pulmonary shunts due to large defects leading to a severe increase in PVR and resulting in a reversed (pulmonary-to-systemic) or bidirectional shunt. Cyanosis, erythrocytosis and multiple organ involvement are present.

B. PAH associated with systemic-to-pulmonary shunts

In these patients with moderate-to-large defects, the increase in PVR is mild to moderate, systemic-to-pulmonary shunt is still largely present, and no cyanosis is present at rest.

\section{PAH with small ${ }^{\#}$ defects}

In cases with small defects (usually ventricular septal defects, $1 \mathrm{~cm}$ and atrial septal defects, $2 \mathrm{~cm}$ of effective diameter assessed by echocardiography) the clinical picture is very similar to idiopathic $\mathrm{PAH}$.

D. PAH after corrective cardiac surgery

In these cases, congenital heart disease has been corrected but PAH is either still present immediately after surgery or has recurred several months or years after surgery in the absence of significant post-operative residual congenital lesions or defects that originate as a sequela to previous surgery.

PVR: pulmonary vascular resistance. ${ }^{*}$ : the size applies to adult patients. Reproduced from [1] with permission from the publisher.

right bundle branch block pattern. 6MWD was $505 \mathrm{~m}$, during which a decrease in arterial oxygen saturation to $87 \%$ was recorded. Echocardiography demonstrated a large atrial septal defect of the posterior ostium secundum $(15 \times 15 \mathrm{~mm})$ associated with a bi-directional shunt that was predominantly right to left. Significant tricuspid regurgitation was also noted and systolic $P$ pa was estimated at $55 \mathrm{mmHg}$. Systemic and pulmonary venous returns were normal. Contrast-enhanced chest $\mathrm{CT}$ was remarkable for massive dilatation of the pulmonary arteries associated with marked right ventricular hypertrophy and dilatation (fig. 3). RHC confirmed PAH with a pre-capillary pattern: $\bar{P}_{\text {pa }} 57 \mathrm{mmHg}, P$ pcw $3 \mathrm{mmHg}$, and PVR $880 \mathrm{dyn} \cdot \mathrm{s} \cdot \mathrm{cm}^{-5}$. The pressures in right and left atria were equivalent at $3 \mathrm{mmHg}$. The pulmonary $\mathrm{CI}$ measured by the Fick method was 3.2 $\mathrm{L} \cdot \mathrm{min}^{-1} \cdot \mathrm{m}^{-2}$ and the systemic CI was $2.6 \mathrm{~L} \cdot \mathrm{min}^{-1} \cdot \mathrm{m}^{-2}$, resulting in a pulmonary to systemic CI ratio of 1.22 . Because of the high level of PVR and the presence of right-to-left shunt, repair surgery was not performed. Instead, oral specific PAH therapy with an endothelin receptor antagonist was initiated. After 6 months, the patient remained in WHO functional class II with a moderate clinical and haemodynamic improvement $(70 \mathrm{~m}$ increase in $6 \mathrm{MWD}$ and $25 \%$ reduction in PVR). Repeat echocardiography confirmed persistence of the right-to-left shunt. Specific PAH therapy was therefore maintained and repair surgery was definitively contraindicated.

\section{Commentary: relevance to ESC/ERS guidelines}

$\mathrm{PAH}$ associated with CHD is included in group 1 of the $\mathrm{PH}$ clinical classification. A specific clinical classification (table 13) and an anatomical-pathophysiological classification (table 14) are useful to better define each individual patient with $\mathrm{PAH}$ associated with CHD. 




ASD: atrial septal defect; VSD: ventricular septal defect. \#: ratio of pulmonary $(Q p)$ to systemic $(Q s)$ blood flow; " : the size applies to adult patients. Modified from [16] with permission from the publisher.

The persistent exposure of the pulmonary vasculature to increased blood flow due to systemic-to-pulmonary shunts as well as increased pressure may result in a typical pulmonary obstructive arteriopathy that leads to the increase of PVR. If PVR approaches or exceeds systemic vascular resistance, the shunt is reversed (Eisenmenger's syndrome).

In patients listed for lung or heart-lung transplantation when no medical treatment was available, Eisenmenger's syndrome had better survival compared with idiopathic PAH, with a 3-yr survival rate of $77 \%$ compared with $35 \%$ for untreated idiopathic PAH.

Recommendations for PAH associated with congenital cardiac shunts are summarised in table 15.

\begin{tabular}{|c|c|c|c|}
\hline \multirow{2}{*}{$\begin{array}{l}\text { TABLE } 15 \\
\text { Statement }\end{array}$} & \multicolumn{3}{|c|}{$\begin{array}{l}\text { ESC/ERS guidelines: recommendations for } \\
\text { pulmonary arterial hypertension associated with } \\
\text { congenital cardiac shunts }\end{array}$} \\
\hline & & Class ${ }^{\#}$ & Level" \\
\hline \multicolumn{2}{|c|}{$\begin{array}{l}\text { The ERA bosentan is indicated in WHO FC III } \\
\text { patients with Eisenmenger's syndrome }\end{array}$} & I & B \\
\hline \multicolumn{2}{|c|}{$\begin{array}{l}\text { Other ERAs, phosphodiesterase type- } 5 \text { inhibitors, } \\
\text { and prostanoids should be considered in patients } \\
\text { with Eisenmenger's syndrome }\end{array}$} & Ila & C \\
\hline \multicolumn{2}{|c|}{$\begin{array}{l}\text { In the absence of significant haemoptysis, oral } \\
\text { anticoagulant treatment should be considered } \\
\text { in patients with PA thrombosis or signs of heart failure }\end{array}$} & Ila & C \\
\hline \multicolumn{2}{|c|}{$\begin{array}{l}\text { The use of supplemental } \mathrm{O}_{2} \text { therapy should be } \\
\text { considered in cases in which it produces a } \\
\text { consistent increase in arterial oxygen } \\
\text { saturation and reduces symptoms }\end{array}$} & Ila & C \\
\hline \multicolumn{2}{|c|}{$\begin{array}{l}\text { If symptoms of hyperviscosity are present, } \\
\text { phlebotomy with isovolumic replacement } \\
\text { should be considered usually when the } \\
\text { haematocrit is }>65 \%\end{array}$} & Ila & C \\
\hline \multicolumn{2}{|c|}{$\begin{array}{l}\text { Combination therapy may be considered in } \\
\text { patients with Eisenmenger's syndrome }\end{array}$} & $\mathrm{llb}$ & C \\
\hline \multicolumn{2}{|c|}{$\begin{array}{l}\text { The use of CCBs is not recommended in patients } \\
\text { with Eisenmenger's syndrome }\end{array}$} & III & C \\
\hline
\end{tabular}

ERA: endothelin receptor antagonist; WHO FC: World Health Organization functional class; PA: pulmonary arterial; CCB: calcium channel blockers. * : class of recommendation; ": level of evidence. Reproduced from [1] with permission from the publisher.

\section{CASE 5: HERITABLE PAH}

\section{Case report}

A 10-yr-old male presented with a 2-month history of progressive dyspnoea on exertion. Clinical examination revealed an accentuated second heart sound over the pulmonic valve. Although the child had no medical history, a strong familial history of PAH had previously been established (fig. 4). 10 yrs earlier, the patient's father had been diagnosed with severe $\mathrm{PAH}$ at age 30 yrs that was initially deemed idiopathic given the absence of familial history at time of diagnosis. However, 2 yrs thereafter, the patient's paternal grandmother was also diagnosed with severe PAH. She had developed symptoms at age 52 yrs, presenting in WHO functional class III with marked haemodynamic impairment. A screening of point mutations and large rearrangements of bone morphogenetic protein receptor type 2 (BMPR2) gene found a c.418+3A $>\mathrm{T}$ mutation (a defect that affects a putative spicing regulatory element in intron 3), thereby confirming the diagnosis of heritable PAH. Genetic counselling sessions were conducted with family members in order to provide information on the risks of developing $\mathrm{PAH}$ and to inform them of disease symptoms and signs. These interventions helped facilitate the early referral of the child to a PAH referral centre in order to expedite a diagnostic work-up. RHC confirmed severe PAH $\left(\bar{P}\right.$ pa $73 \mathrm{mmHg}, \mathrm{CI} 2.71 \mathrm{~L} \cdot \mathrm{min}^{-1} \cdot \mathrm{m}^{-2}$ and PVR $\left.1,510 \mathrm{dyn} \cdot \mathrm{s} \cdot \mathrm{cm}^{-5}\right)$ and endothelin receptor antagonist therapy was initiated. However, after 6 months of treatment there was only a modest 


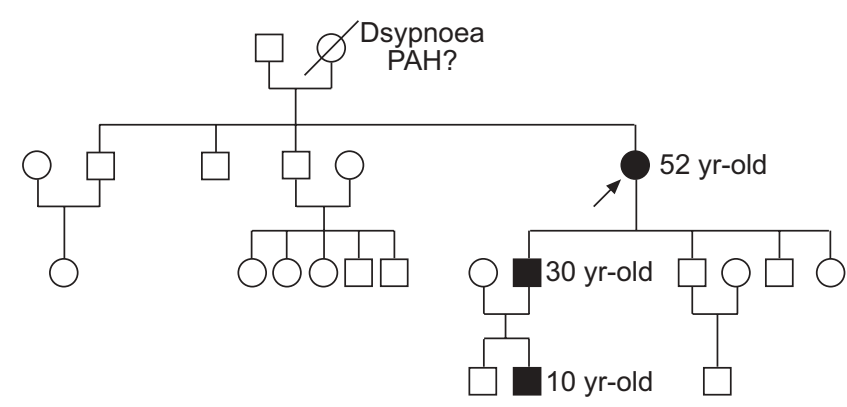

FIGURE 4. Genealogical tree of heritable pulmonary arterial hypertension $(\mathrm{PAH})$ with BMPR2 mutation, demonstrating the phenomenon of genetic anticipation. $\mathrm{PAH}$ in the first generation was diagnosed at age $52 \mathrm{yrs}$, then at age $30 \mathrm{yrs}$ in the second generation and at age 10 yrs for the last generation.

clinical and haemodynamic improvement, justifying the addition of a phosphodiesterase-5 (PDE-5) inhibitor.

\section{Commentary: relevance to ESC/ERS guidelines}

When PAH occurs in a familial context, germline mutations in the BMPR2 gene are detected in $\geqslant 70 \%$ of cases.

Mutations of this gene can also be detected in $11-40 \%$ of apparently sporadic cases, thus representing the major genetic predisposing factor for PAH.

The BMPR2 gene encodes a type 2 receptor for bone morphogenetic proteins, which belong to the transforming growth factor- $\beta$ superfamily, involved in the control of vascular cell proliferation.

Mutations of other receptors for these substances, such as activin receptor-like kinase 1 ( $A L K-1$ or $A C V R L-1$ ) and endoglin, have been identified mostly in $\mathrm{PAH}$ patients with a personal or family history of hereditary haemorrhagic telangiectasia (Osler-Weber-Rendu syndrome).

\section{CASE 6: CHRONIC THROMBOEMBOLIC PULMONARY HYPERTENSION}

\section{Case report}

A 21-yr-old male professional soccer player presented with a 1yr history of exercise intolerance and intermittent pleuritic chest pain. He was a cigarette smoker (2 pack-yrs) but otherwise had no significant past medical history, denied previous illicit or performance-enhancing drug intake and had no personal or family history of venous thromboembolism. Initial chest radiograph, PFTs and echocardiography were negative and no further exams were performed. The patient represented 18 months later with worsening of breathlessness. Repeat echocardiography showed moderately dilated right heart chambers with an estimated systolic Ppa of $55 \mathrm{mmHg}$. A working diagnosis of pulmonary embolism was made; however, both CT pulmonary angiography and lower limb compression ultrasonography were normal. 1 month later, he represented with severe pleuritic chest pain. On this occasion, ventilation/perfusion lung scintigraphy confirmed bilateral pulmonary emboli and compression ultrasonography identified a left leg deep vein thrombosis. Anticoagulation therapy was therefore initiated. 4 months thereafter, the patient had persistent WHO functional class II symptoms. Repeat echocardiography demonstrated persistent $\mathrm{PH}$ (systolic $\mathrm{Ppa}$ $60 \mathrm{mmHg}$ ). 6MWD was $540 \mathrm{~m}$. Thrombophilia screening was negative. RHC confirmed mild $\mathrm{PH}$ at rest with a significant increase in $\bar{P}_{\text {pa }}$ with exercise at $100 \mathrm{~W}$ (table 16). Repeat CTPA and formal pulmonary angiography confirmed the presence of chronic thromboembolic disease in a proximal distribution (fig. $5 \mathrm{a}$ and $\mathrm{b}$ ) and treatment by pulmonary thromboendarterectomy (PEA) was proposed. However, the patient declined surgery, though agreed to continue oral anticoagulation. 18 months later, he was readmitted with increasing breathlessness. The patient was in WHO functional class III and 6MWD was $477 \mathrm{~m}$ (decrease of $63 \mathrm{~m}$ from baseline). Haemodynamic reassessment confirmed worsening $\mathrm{PH}$ (table 16) while progressive occlusive vasculopathy was noted

\section{TABLE 16 Case 6: clinical data}

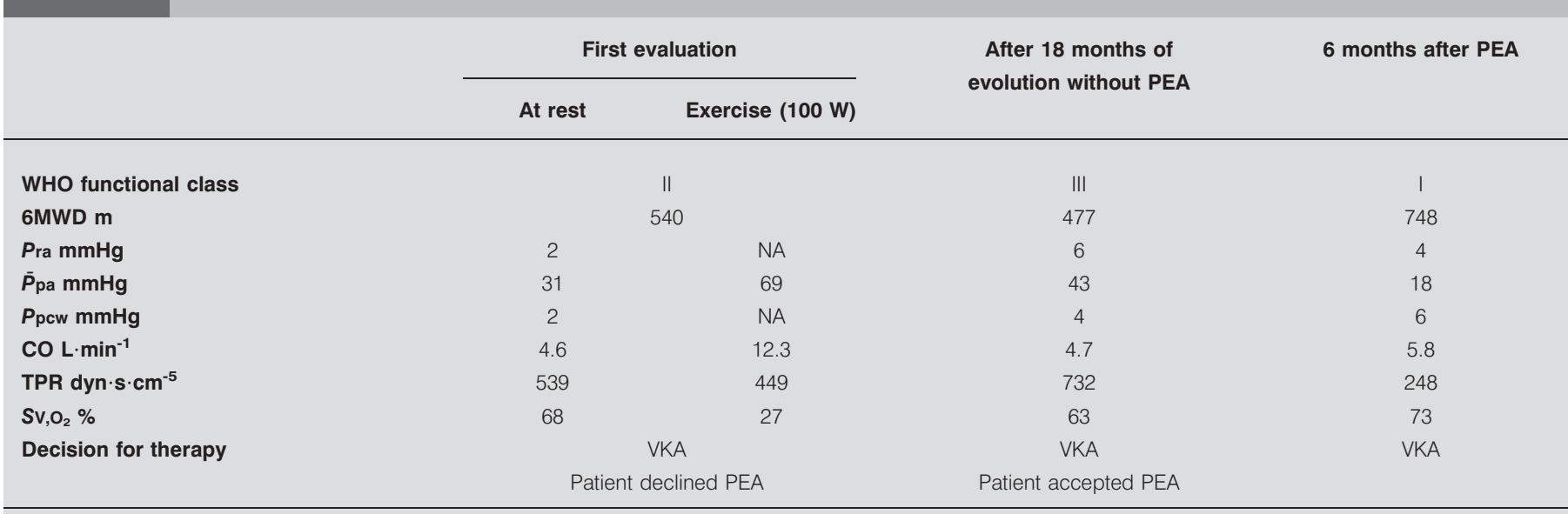

PEA: pulmonary thromboendarterectomy; WHO: World Health Organization; 6MWD: 6-min walk distance; Pra: right atrial pressure; $\bar{P}$ pa: mean pulmonary arterial pressure Ppcw: pulmonary capillary wedge pressure; $\mathrm{CO}$ : cardiac output; TPR: total pulmonary resistance; $\mathrm{SV}, \mathrm{O}_{2}$ : mixed venous oxygen saturation; VKA: oral vitamin $\mathrm{K}$ antagonist anticoagulation. 

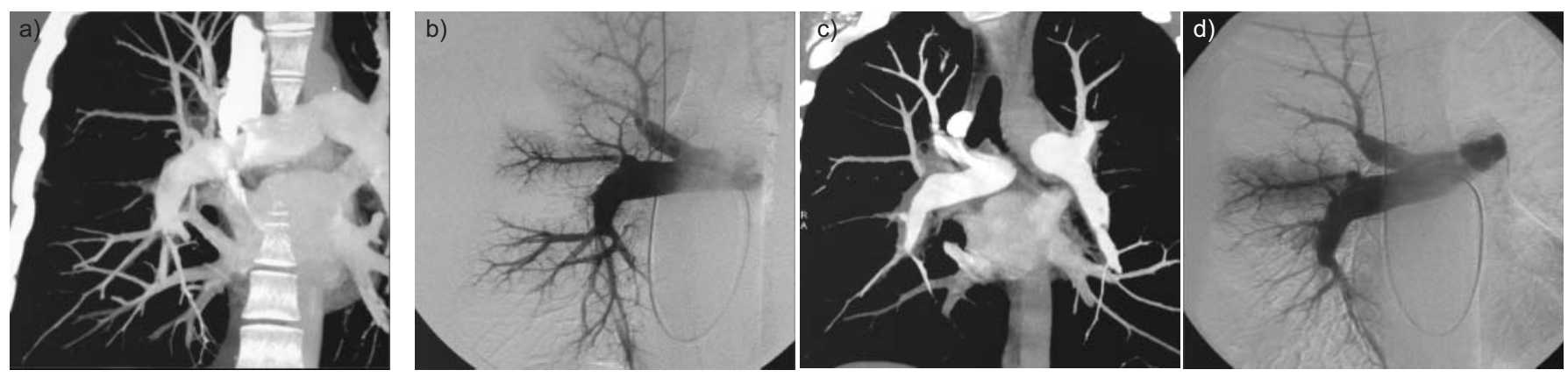

FIGURE 5. Case 6. a) Computed tomography pulmonary angiography and b) formal pulmonary angiography confirmed the presence of chronic thromboembolic disease. c) and d) Progressive occlusive vasculopathy was noted on repeat imaging studies.

on repeat imaging studies (fig. $5 \mathrm{c}$ and $\mathrm{d}$ ). On this occasion, the patient proceeded to PEA during which obstructing material was successfully removed from all major pulmonary artery branches. His post-operative course was unremarkable and oral anticoagulation was recommenced. At follow-up 6 months later, he was asymptomatic and repeat RHC confirmed normal pulmonary haemodynamics (table 16).

\section{Commentary: relevance to ESC/ERS guidelines}

$\mathrm{CTEPH}$ is one of the most prevalent forms of PH. Nevertheless, it is almost impossible to determine the overall prevalence of CTEPH since not all of these patients have a history of acute pulmonary embolism.

Any patient with unexplained $\mathrm{PH}$ should be evaluated for the presence of CTEPH. 1) A normal ventilation/perfusion scan rules out CTEPH. 2) Multi-row CT angiography is indicated when the ventilation/perfusion lung scan is indeterminate or reveals perfusion defects. Even in the era of modern multi-row CT scanners, there is not yet enough evidence to suggest that a normal CT angiography excludes the presence of operable CTEPH.

Once ventilation/perfusion scanning and/or CT angiogram show signs compatible with CTEPH, the patient should be referred to a centre with expertise in the medical and surgical management of these patients.

To determine the appropriate therapeutic strategy, invasive tools, including RHC and traditional pulmonary angiography, are usually required. The final diagnosis of CTEPH is based on the presence of pre-capillary $\mathrm{PH}$ in patients with multiple chronic/organised occlusive thrombi/emboli in the elastic pulmonary arteries (main, lobar, segmental and subsegmental).

The decision on how to treat patients with CTEPH should be made at an experienced centre based upon interdisciplinary discussion among internists, radiologists, and expert surgeons: 1) PEA is the treatment of choice for patients with CTEPH, as it is a potentially curative option; 2) patients with CTEPH should receive life-long anticoagulation, usually with vitamin $\mathrm{K}$ antagonists adjusted to a target INR of 2.0-3.0.

Recommendations for PH due to CTEPH are summarised in table 17.

\section{CASE 7: ACUTE VASOREACTIVITY TEST RESPONDER Case report}

A 69-yr-old female presented with a 3-month history of dyspnoea and exercise intolerance. Her past medical history was significant for breast cancer diagnosed 2 yrs previously treated by surgery and adjuvant combination cytotoxic therapy with cyclophosphamide, 5-fluoro-uracil and farmorubicin. At the time of initial referral, she was in WHO functional class III.

\begin{tabular}{|c|c|c|c|}
\hline TABLE 17 & $\begin{array}{l}\text { ESC/ERS guidelines: recomme } \\
\text { chronic thromboembolic pulmc } \\
\text { hypertension (CTEPH) }\end{array}$ & $\begin{array}{l}\text { dations } \\
\text { ary }\end{array}$ & \\
\hline \multicolumn{2}{|l|}{ Statement } & Class $^{\#}$ & Level ${ }^{\circ}$ \\
\hline \multicolumn{2}{|c|}{$\begin{array}{l}\text { The diagnosis of CTEPH is based on the presence } \\
\text { of pre-capillary } \mathrm{PH}\left(\bar{P}_{\mathrm{pa}} \geqslant 25 \mathrm{mmHg}, P \mathrm{pcw}\right. \\
\leqslant 15 \mathrm{mmHg}, \mathrm{PVR}>2 \text { Wood units) in patients with } \\
\text { multiple chronic/organised occlusive thrombi/ } \\
\text { emboli in the elastic pulmonary arteries (main, } \\
\text { lobar, segmental, subsegmental) }\end{array}$} & I & C \\
\hline \multicolumn{2}{|c|}{$\begin{array}{l}\text { In patients with CTEPH lifelong anticoagulation } \\
\text { is indicated }\end{array}$} & I & C \\
\hline \multicolumn{2}{|c|}{$\begin{array}{l}\text { Surgical pulmonary endarterectomy is the } \\
\text { recommended treatment for patients with CTEPH }\end{array}$} & I & C \\
\hline \multicolumn{2}{|c|}{$\begin{array}{l}\text { Once perfusion scanning and/or CT } \\
\text { angiography show signs compatible with } \\
\text { CTEPH, the patient should be referred to a } \\
\text { centre with expertise in surgical } \\
\text { pulmonary endarterectomy }\end{array}$} & Ila & C \\
\hline \multicolumn{2}{|c|}{$\begin{array}{l}\text { The selection of patients for surgery should be } \\
\text { based on the extent and location of the } \\
\text { organised thrombi, on the degree of } \mathrm{PH} \text {, and } \\
\text { on the presence of comorbidities }\end{array}$} & Ila & C \\
\hline \multicolumn{2}{|c|}{$\begin{array}{l}\text { PAH-specific drug therapy may be indicated in } \\
\text { selected CTEPH patients such as patients not } \\
\text { candidates for surgery or patients with residual } \\
\text { PH after pulmonary endarterectomy }\end{array}$} & llb & C \\
\hline
\end{tabular}

$\mathrm{PH}$ : pulmonary hypertension; $\bar{P}$ pa: mean pulmonary arterial pressure; $P$ pow: pulmonary capillary wedge pressure; PVR: pulmonary vascular resistance; $\mathrm{CT}$ : computed tomography; PAH: pulmonary arterial hypertension. *: class of recommendation; $"$ : level of evidence. Reproduced from [1] with permission from the publisher. 


\begin{tabular}{|c|c|c|c|c|}
\hline & At rest & Acute vasodilator testing & At rest & Acute vasodilator testing \\
\hline WHO functional class & & III & & $\|$ \\
\hline 6MWD m & & 210 & & 310 \\
\hline Pra $\mathrm{mmHg}$ & 6 & 5 & 6 & 6 \\
\hline $\mathrm{CO} L \cdot \mathrm{min}^{-1}$ & 6.6 & 7.3 & 7.0 & 6.8 \\
\hline PVR dyn $\cdot \mathbf{s} \cdot \mathrm{cm}^{-5}$ & 509 & 208 & 286 & 200 \\
\hline
\end{tabular}

CCB: calcium channel blockers; WHO: World Health Organization; 6MWD: 6-min walk distance; Pra: right atrial pressure; $\bar{P}$ pa: mean pulmonary arterial pressure; Ppcw: pulmonary capillary wedge pressure; $\mathrm{CO}$ : cardiac output; PVR: pulmonary vascular resistance.

Clinical examination revealed an accentuated second heart sound over the pulmonic valve without evidence of cardiac failure. Transthoracic echocardiography estimated systolic $P$ pa $62 \mathrm{mmHg}$. Additional routine diagnostic testing for an underlying cause of $\mathrm{PH}$ was negative. The patient proceeded to RHC in order to confirm the diagnosis and assess severity of haemodynamic impairment. This revealed severe pre-capillary PH $\left(\bar{P}_{\text {pa }} 52 \mathrm{mmHg}\right.$ and PVR 509 dyn $\left.\cdot \mathrm{s} \cdot \mathrm{cm}^{-5}\right)$ with a preserved $\mathrm{CO}$ and no evidence of hypervolaemia (table 18). An acute vasodilator challenge testing using inhaled nitric oxide at a dose of $10 \mathrm{ppm}$ was then performed to assess for vasoreactivity. This showed a significant acute vasodilator response with near normalisation of $\bar{P}$ pa, reduction in PVR and an associated increase in CI (table 18). A treatment with high-dose oral calcium channel antagonist (CCB) therapy was therefore initiated and titrated up to the maximum tolerated dose, in conjunction with oral anticoagulation. At haemodynamic reassessment 12 months later, the patient had improved to WHO functional class II and had increased her 6MWD from $210 \mathrm{~m}$ to $310 \mathrm{~m}$. Subsequent RHC confirmed a sustained favourable pulmonary haemodynamic response and the dose of oral CCB was increased because of persistence of an acute vasoreactivity to inhaled nitric oxide.

\section{Commentary: relevance to ESC/ERS guidelines}

In PAH, vasoreactivity testing should be performed at the time of diagnostic RHC to identify patients who may benefit from long-term therapy with CCBs.
Acute vasodilator challenge should only be performed with short-acting, safe and easy to administer drugs with no or limited systemic effects. Currently the agent most used in acute testing is nitric oxide based on previous experience; i.v. epoprostenol or i.v. adenosine may also be used as an alternative (but with a risk of systemic vasodilator effects) (table 19). Due to the risk of potentially life-threatening complications, the use of CCBs given orally or i.v. as an acute test is discouraged.

A positive acute response (positive acute responder) is defined as a reduction of $\bar{P}_{\mathrm{pa}} \geqslant 10 \mathrm{mmHg}$ to reach an absolute value of $\bar{P}_{\text {pa }} \leqslant 40 \mathrm{mmHg}$ with an increased or unchanged CO. Only $10 \%$ of patients with idiopathic PAH will meet these criteria (table 20).

Positive acute responders are most likely to show a sustained response to long-term treatment with high doses of CCBs and they are the only patients that can safely be treated with this type of therapy. About half of idiopathic PAH-positive acute responders are also positive long-term responders to CCBs and only in these cases is the continuation of a $\mathrm{CCB}$ as a single treatment warranted.

The usefulness of acute vasoreactivity tests and long-term treatment with CCBs in patients with other PAH types, such as heritable PAH, CTD, and HIV patients is less clear than in idiopathic PAH. Nevertheless, experts recommend performing acute vasoreactivity studies in these patients and to look for a long-term response to CCBs in those in whom the test is positive.

TABLE 19 ESC/ERS guidelines: route of administration, half-life, dose ranges, increments and duration of administration of the most commonly used agents for pulmonary vasoreactivity tests

\begin{tabular}{lcccc} 
Drug & Route & Half-life & Dose range & Increments $^{*}$ \\
\hline Epoprostenol & Intravenous & $3 \mathrm{~min}$ & $2-12 \mathrm{ng} \cdot \mathrm{kg}^{-1} \cdot \mathrm{min}^{-1}$ & $2 \mathrm{ng} \cdot \mathrm{kg}^{-1} \cdot \mathrm{min}^{-1}$ \\
Adenosine & Intravenous & $5-10 \mathrm{~s}$ & $50-350 \mu \mathrm{gg} \cdot \mathrm{kg}^{-1} \cdot \mathrm{min}^{-1}$ & $50 \mu \mathrm{gg} \cdot \mathrm{kg}^{-1} \cdot \mathrm{min}^{-1}$ \\
Nitric oxide & Inhaled & $15-30 \mathrm{~s}$ & $10-20 \mathrm{ppm}$ & $2 \mathrm{~min}$ \\
\hline
\end{tabular}

\#: initial dose and maximal tolerated dose suggested (maximal dose limited by side-effects such as hypotension, headache, flushing, etc.); ": increments of dose by each step; $^{+}$: duration of administration on each step; ${ }^{5}$ : for nitric oxide, a single step within the dose range is suggested. Reproduced from [1] with permission from the publisher 


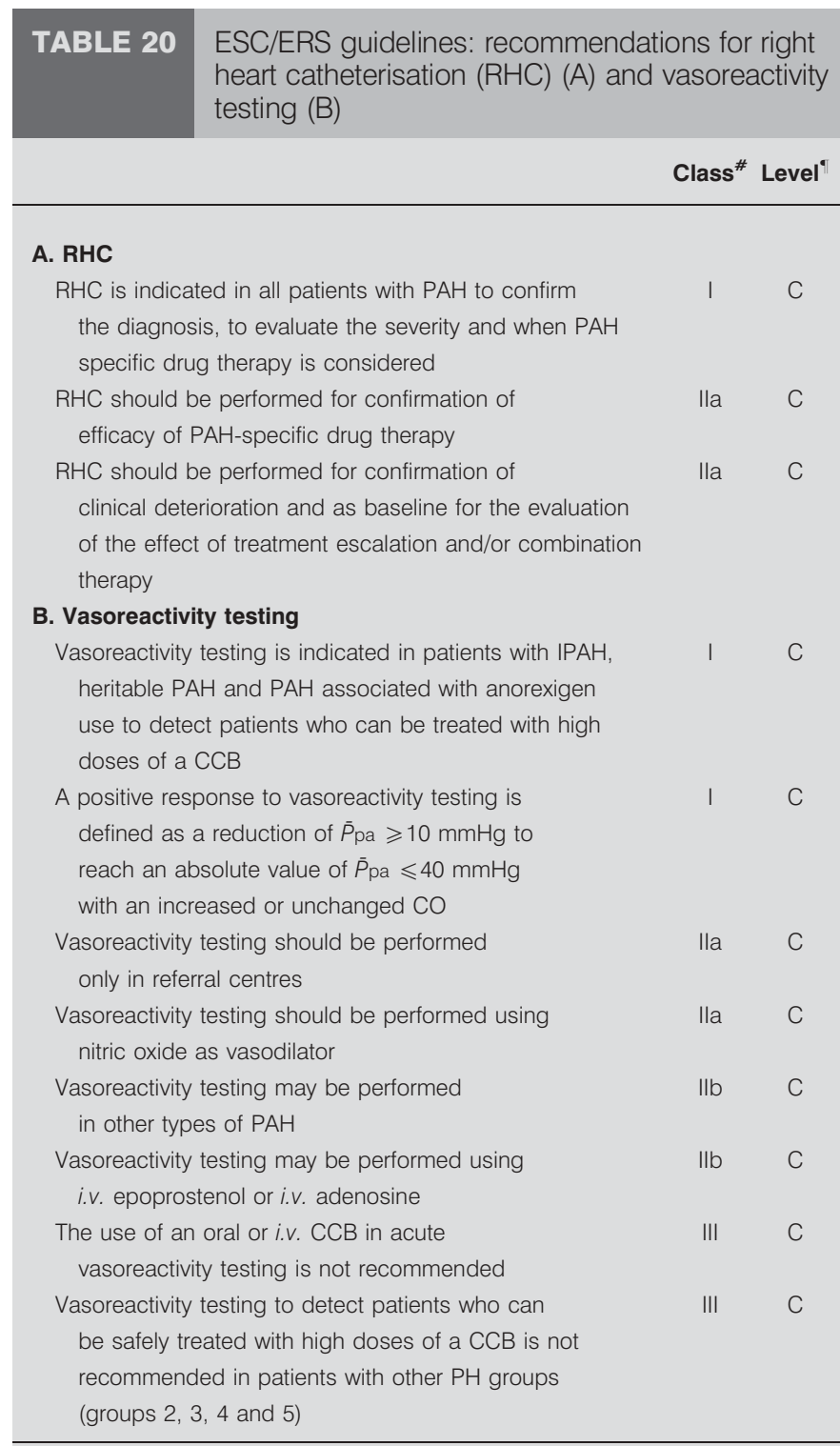

$\mathrm{PAH}$ : pulmonary arterial hypertension; IPAH: idiopathic pulmonary arterial hypertension; CCB: calcium channel blocker; $\bar{P}_{\text {pa: }}$ mean pulmonary arterial pressure; $\mathrm{CO}$ : cardiac output; $\mathrm{PH}$ : pulmonary hypertension. \#: class of recommendation; $"$ : level of evidence. Reproduced from [1] with permission from the publisher.

The CCBs that have been predominantly used in reported studies are nifedipine, diltiazem, and amlodipine, with particular emphasis on the first two. The choice of CCB is based upon the patient's heart rate at baseline, with a relative bradycardia favouring nifedipine and amlodipine and a relative tachycardia favouring diltiazem. The daily doses of these drugs that have shown efficacy in idiopathic PAH are relatively high, $120-240 \mathrm{mg}$ for nifedipine, $240-720 \mathrm{mg}$ for diltiazem, and up to $20 \mathrm{mg}$ for amlodipine.

Patients with idiopathic PAH who meet the criteria for a positive vasodilator response and are treated with a CCB should be followed closely for both safety and efficacy with an initial reassessment after 3-4 months of therapy including

\section{TABLE 21 ESC/ERS guidelines: recommendations for general measures}

\begin{tabular}{|c|c|c|}
\hline Statement & Class $^{\#}$ & Level" \\
\hline $\begin{array}{l}\text { It is recommended to avoid pregnancy in patients } \\
\text { with PAH }\end{array}$ & I & C \\
\hline $\begin{array}{l}\text { Immunisation of PAH patients against influenza } \\
\text { and pneumococcal infection is recommended }\end{array}$ & 1 & C \\
\hline $\begin{array}{l}\text { Physically deconditioned PAH patients should be } \\
\text { considered for supervised exercise rehabilitation }\end{array}$ & Ila & B \\
\hline $\begin{array}{l}\text { Psychosocial support should be considered in } \\
\text { patients with PAH }\end{array}$ & Ila & C \\
\hline $\begin{array}{l}\text { In-flight } \mathrm{O}_{2} \text { administration should be considered } \\
\text { for patients in WHO FC III and IV and those with } \\
\text { arterial blood } \mathrm{O}_{2} \text { pressure consistently } \\
<8 \mathrm{kPa}(60 \mathrm{mmHg})\end{array}$ & Ila & C \\
\hline $\begin{array}{l}\text { Epidural anaesthesia instead of general } \\
\text { anaesthesia should be utilised, if possible, for } \\
\text { elective surgery }\end{array}$ & Ila & C \\
\hline $\begin{array}{l}\text { Excessive physical activity that leads to distressing } \\
\text { symptoms is not recommended in patients with PAH }\end{array}$ & III & C \\
\hline
\end{tabular}

RHC. If the patient does not show an adequate response, defined as being in WHO functional class I or II and with a marked haemodynamic improvement, additional PAH therapy should be instituted.

Patients who have not undergone a vasoreactivity study or those with a negative study should not be started on a CCB because of potential severe side-effects.

\section{CASE 8: IDIOPATHIC PAH WITH WHO FUNCTIONAL CLASS II SYMPTOMS \\ Case report}

A 48-yr-old male was referred for evaluation of breathlessness associated with effort-associated palpitations and chest discomfort. He reported that his symptoms occurred with moderate exertion and was therefore deemed to be in WHO functional class II. He denied dizziness, syncope or ankle swelling. The only positive sign elicited on physical examination was an accentuated pulmonary component to the second heart sound. Baseline 6MWD was $450 \mathrm{~m}$. RHC confirmed precapillary $\mathrm{PH}$ of moderate severity without associated acute vasodilator response (right atrial pressure $2 \mathrm{mmHg}, \bar{P}_{\text {pa }}$ $35 \mathrm{mmHg}, \quad P$ pcw $5 \mathrm{mmHg}, \quad$ PVR $260 \mathrm{dyn} \cdot \mathrm{s} \cdot \mathrm{cm}^{-5}$ and CI $\left.5.6 \mathrm{~L} \cdot \mathrm{min}^{-1} \cdot \mathrm{m}^{-2}\right)$. Routine testing to assess for underlying causes of $\mathrm{PH}$ was negative and a diagnosis of idiopathic $\mathrm{PAH}$ was made. He was commenced on PAH-specific therapy with an endothelin antagonist in addition to oral anticoagulation. At reassessment after 6 months of treatment, he remained in WHO functional class II, had a 6MWD of $466 \mathrm{~m}$ and showed a stable pulmonary haemodynamic profile (right atrial pressure $7 \mathrm{mmHg}$; $\bar{P}_{\text {pa }} 39 \mathrm{mmHg}$; Ppcw $8 \mathrm{mmHg}$; PVR $238 \mathrm{dyn} \cdot \mathrm{s} \cdot \mathrm{cm}^{-5}$ and CI $5.8 \mathrm{~L} \cdot \mathrm{min}^{-1} \cdot \mathrm{m}^{-2}$ ). He was reassessed thereafter on a 6-monthly basis. On each occasion, he was 


\begin{tabular}{|c|c|c|c|}
\hline \multirow{2}{*}{$\begin{array}{l}\text { TABLE } 22 \\
\text { Statement }\end{array}$} & \multicolumn{3}{|c|}{$\begin{array}{l}\text { ESC/ERS guidelines: recommendations for } \\
\text { supportive therapy }\end{array}$} \\
\hline & & Class $^{\#}$ & Level" \\
\hline \multicolumn{2}{|c|}{$\begin{array}{l}\text { Diuretic treatment is indicated in PAH patients } \\
\text { with signs of RV failure and fluid retention }\end{array}$} & I & C \\
\hline \multicolumn{2}{|c|}{$\begin{array}{l}\text { Continuous long-term } \mathrm{O}_{2} \text { therapy is indicated } \\
\text { in PAH patients when arterial blood } \mathrm{O}_{2} \text { pressure } \\
\text { is consistently }<8 \mathrm{kPa}(60 \mathrm{mmHg})^{+}\end{array}$} & 1 & C \\
\hline \multicolumn{2}{|c|}{$\begin{array}{l}\text { Oral anticoagulant treatment should be } \\
\text { considered in patients with IPAH, heritable } \\
\text { PAH and PAH due to use of anorexigens }\end{array}$} & Ila & C \\
\hline \multicolumn{2}{|c|}{$\begin{array}{l}\text { Oral anticoagulant treatment may be } \\
\text { considered in patients with APAH }\end{array}$} & $11 \mathrm{~b}$ & C \\
\hline \multicolumn{2}{|c|}{$\begin{array}{l}\text { Digoxin may be considered in patients with } \\
\text { PAH who develop atrial tachyarrhythmias to } \\
\text { slow ventricular rate }\end{array}$} & Ilb & C \\
\hline
\end{tabular}

PAH: pulmonary arterial hypertension; RV: right ventricular; IPAH: idiopathic PAH; APAH: associated PAH. * : class of recommendation; ": level of evidence; ${ }^{+}$: see also recommendations for PAH associated with congenital cardiac shunts (table 15). Reproduced from [1] with permission from the publisher.

noted to be in WHO functional class II and had stable exercise capacity, as evidenced by 6MWD consistently in the 475-500 m range. Treatment was therefore continued without modification. Since diagnosis of PAH 5 yrs ago, the patient has shown no evidence of clinical or haemodynamic deterioration.

\section{Commentary: relevance to ESC/ERS guidelines}

The management of $\mathrm{PAH}$ patients includes general and supportive measures, as follows. 1) Patients should avoid excessive physical activity that leads to distressing symptoms, but when physically deconditioned may undertake supervised exercise rehabilitation. 2) Pregnancy is associated with 30-50\% mortality in patients with $\mathrm{PAH}$ and, as a consequence, pregnancy is contraindicated in PAH. There is less consensus relating to the most appropriate methods of birth control. Barrier contraceptive methods are safe and progesterone-only preparations are effective approaches to contraception and avoid potential issues of oestrogens. 3) Patients should avoid going to altitudes above 1,500-2,000 $\mathrm{m}$ without supplemental oxygen. 4) It is recommended to vaccinate against influenza and pneumococcal pneumonia.

Recommendations for general measures are summarised in table 21 .

Advice regarding the target INR in patients with idiopathic PAH varies from 1.5-2.5 in most centres of North America to 2.0-3.0 in European centres.

Diuretic treatment is indicated in PAH patients with signs of right ventricular failure and fluid retention.

When arterial blood oxygen pressure is consistently $<8 \mathrm{kPa}$ $(60 \mathrm{mmHg})$ patients are advised to take oxygen to achieve a arterial blood oxygen pressure of. $8 \mathrm{kPa}$ for $\geqslant 15 \mathrm{~h} \cdot$ day $^{-1}$.

Recommendations for general measures are summarised in table 22 .

\section{TABLE 23 ESC/ERS guidelines: recommendations for efficacy of specific drug therapy, balloon atrial septostomy and lung transplantation for pulmonary arterial hypertension (group 1) according to World Health Organization functional class (WHO FC)}

Measure/treatment

Prostanoids

Initial drugs combination therapy

Sequential drugs combination therapy

Balloon atrial septostomy
Lung transplantation

Classes of recommendation-level of evidence

\begin{tabular}{|c|c|c|}
\hline WHO FC II & WHO FC III & WHO FC IV \\
\hline $1-C^{\#}$ & $1-C^{\#}$ & - \\
\hline I-A & $\mathrm{I}-\mathrm{A}$ & $\| \mathrm{a}-\mathrm{C}$ \\
\hline I-A & $\mathrm{I}-\mathrm{A}$ & $\| \mathrm{la}-\mathrm{C}$ \\
\hline $\mathrm{Ila}-\mathrm{C}$ & $\mathrm{I}-\mathrm{A}$ & $\mathrm{Ila}-\mathrm{C}$ \\
\hline I-A & $1-A$ & $\| \mathrm{la}-\mathrm{C}$ \\
\hline I-B & I-B & $\| \mathrm{I}-\mathrm{C}$ \\
\hline - & llb-B & - \\
\hline- & $\mathrm{I}-\mathrm{A}$ & I-A \\
\hline- & $1-A$ & $11 \mathrm{a}-\mathrm{C}$ \\
\hline- & IIa-C & $\| \mathrm{I}-\mathrm{C}$ \\
\hline- & I-B & IIa-C \\
\hline- & IIa-C & IIa-C \\
\hline- & I-B & Ila-C \\
\hline- & - & $\| \mathrm{I}-\mathrm{C}$ \\
\hline $\mathrm{Ila}-\mathrm{C}$ & Ila-B & lia-B \\
\hline- & $\mathrm{I}-\mathrm{C}$ & $\mathrm{I}-\mathrm{C}$ \\
\hline - & $\mathrm{I}-\mathrm{C}$ & I-C \\
\hline
\end{tabular}

\#: only in responders to acute vasoreactivity tests, I for idiopathic pulmonary arterial hypertension (PAH), heritable PAH and PAH due to anorexigens; Ila for associated PAH conditions; $\because$ : under regulatory review in the European Union. Reproduced from [1] with permission from the publisher. 


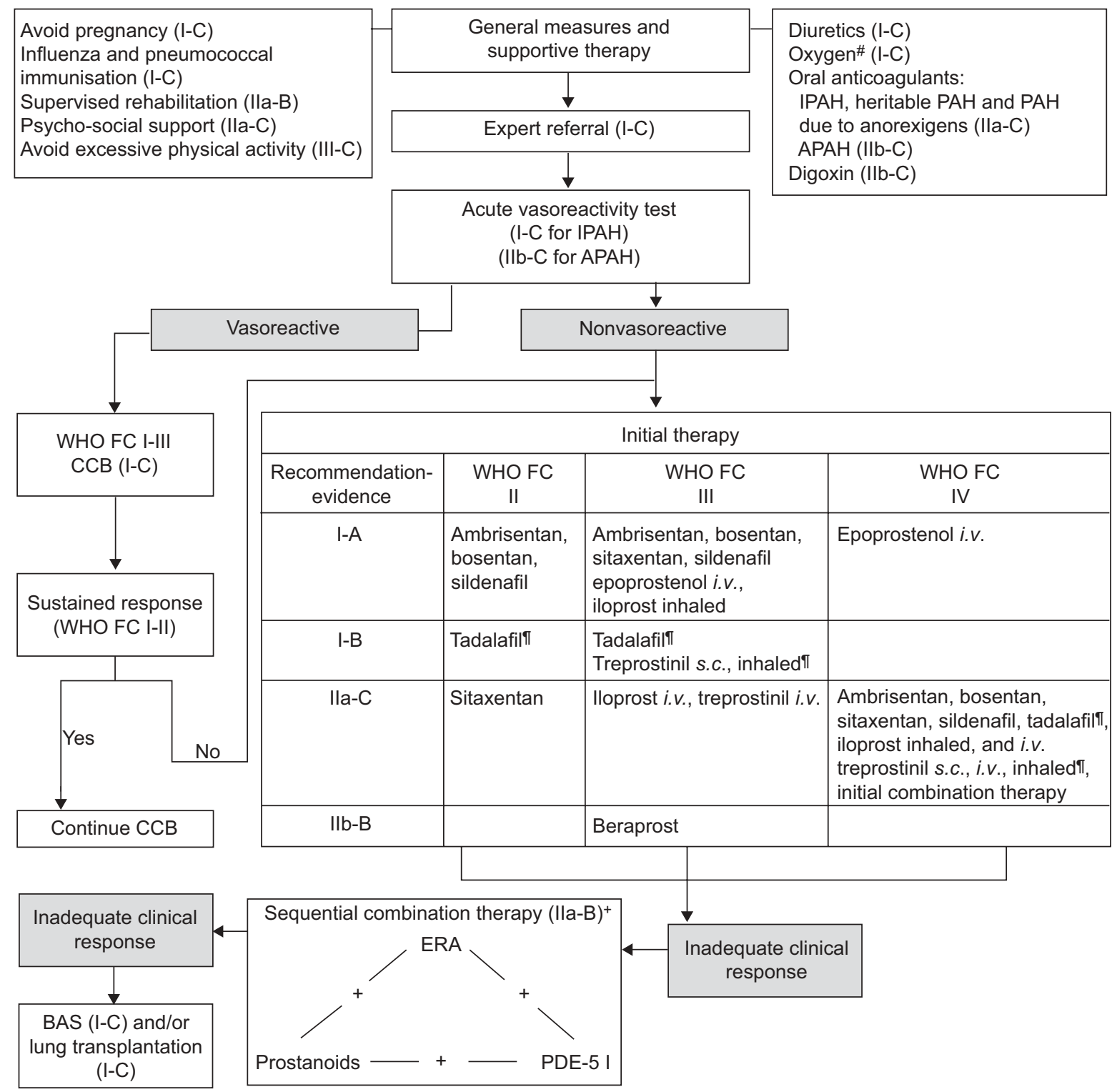

FIGURE 6. Evidence-based treatment algorithm for pulmonary arterial hypertension patients (PAH; for group 1 patients only). APAH: associated PAH; BAS: balloon atrial septostomy; CCB: calcium channel blocker; ERA: endothelin receptor antagonist; IPAH: idiopathic PAH; PDE-5I: phosphodiesterase type-5 inhibitor; WHO FC: World Health Organization functional class. \#: to maintain arterial blood $\mathrm{O}_{2}$ pressure $>8 \mathrm{kPa}(60 \mathrm{mmHg})$; ${ }^{\circ}$ : under regulatory review in the European Union; ${ }^{+}$: Ila-C for WHO FC II. Reproduced from [1] with permission from the publisher.

As head-to-head comparisons among different compounds are not available, no evidence-based first-line treatment can be proposed. In this case the choice of the drug is dependent on a variety of factors, including the approval status, the route of administration, the side-effect profile, patients' preferences and physicians' experience.

Classes of recommendations and level of evidence for first-line therapy in $\mathrm{PAH}$ patients (group 1) depends on the WHO functional class (table 23). Nonresponders to acute vasoreactivity testing who are in WHO functional class II should be treated with an endothelin receptor agonist or a PDE-5 inhibitor.

\section{CASE 9: IDIOPATHIC PAH WITH WHO FUNCTIONAL CLASS IV SYMPTOMS TREATED BY FIRST-LINE COMBINATION THERAPY \\ Case report}

A 27-yr-old female with previously well-controlled asthma since childhood was referred for evaluation of a 1-month history of progressive dyspnoea unresponsive to augmentation of inhaled corticosteroids. There was no family history of pulmonary vascular disease. At presentation she was in WHO functional class IV, being breathless on minimal exertion and having experienced several pre-syncopal episodes. Physical examination revealed a loud pulmonic component to the second heart sound and a soft pansystolic murmur over the tricuspid valve without 
TABLE 24 Case 10: clinical characteristics

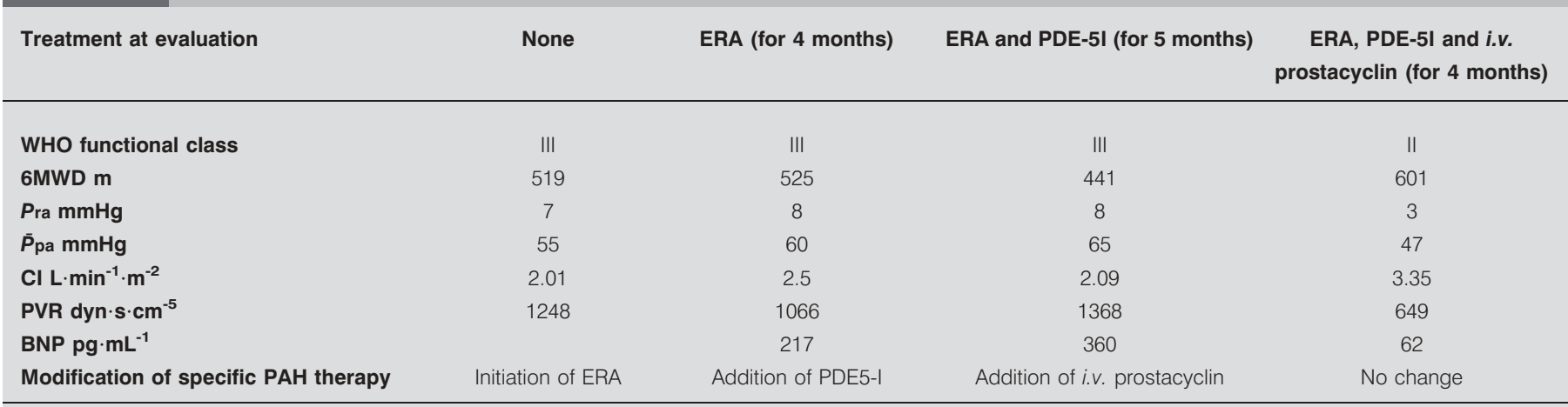

ERA: endothelin receptor agonist; PDE5-I: phosphodiesterase type-5 inhibitor; WHO: World Health Organization; 6MWD: 6-min walk distance; Pra: right atrial pressure Pिpa: mean pulmonary arterial pressure; Cl: cardiac index; PVR: pulmonary vascular resistance; BNP: brain natriuretic peptide; PAH: pulmonary arterial hypertension.

jugular venous distension or peripheral oedema. Chest radiograph demonstrated an enlarged heart and clear lung fields. Transthoracic echocardiography revealed a systolic $P$ pa $>100 \mathrm{mmHg}$ and associated dilated right heart chambers without evidence of intracardiac shunt. Arterial blood gas analysis showed a respiratory alkalosis pattern and hypoxaemia. Antinuclear antibody, anti-double-stranded DNA, rheumatoid factor and HIV test were negative. Abdominal ultrasound showed no evidence of portal hypertension. PFTs demonstrated normal airway function and lung volumes, but a DL,CO of $60 \%$ pred. Lung scintigraphy was unremarkable. The patient's 6MWD was $150 \mathrm{~m}$, during which an oxygen desaturation to $81 \%$ was recorded, despite the use of supplementary oxygen. RHC confirmed severe pre-capillary $\mathrm{PH}$ with $\bar{P}_{\text {pa }} 74 \mathrm{mmHg}, \mathrm{PVR}$ $1,450 \mathrm{dyn} \cdot \mathrm{s} \cdot \mathrm{cm}^{-5}$, CI $1.9 \mathrm{~L} \cdot \mathrm{min}^{-1} \cdot \mathrm{m}^{-2}$ and a mixed venous oxygen saturation of $57 \%$. Acute vasodilator testing with nitric oxide was negative. Because of the severity of the patient's symptoms, advanced functional class, marked limitation of exercise capacity and significant haemodynamic impairment, a decision was made to initiate a dual targeted therapy regimen with combination continuous i.v. prostacyclin and oral endothelin antagonist.

\section{Commentary: relevance to ESC/ERS guidelines}

The treatment algorithm (fig. 6) does not apply to patients in other clinical groups, and in particular not to patients with $\mathrm{PH}$ associated with group 2 (left heart disease) or with group 3 (lung diseases). In addition, the different treatments have been evaluated by randomised controlled trials mainly in idiopathic $\mathrm{PAH}$, heritable $\mathrm{PAH}, \mathrm{PAH}$ due to anorexigen drugs, and in PAH associated with CTD or with CHD (surgically corrected or not). The grades of recommendation and levels of evidence for the other PAH subgroups are lower.

The suggested initial approach after the diagnosis of PAH is the adoption of the general measures, the initiation of the supportive therapy and referral to an expert centre. Acute vasoreactivity testing should be performed in all patients with group 1 PAH. Vasoreactive patients should be treated with optimally tolerated doses of CCBs.

Nonresponders to acute vasoreactivity testing, or responders who remain in (or progress to) WHO functional class III should be considered candidates for treatment with an endothelin receptor agonist, a PDE-5 inhibitor, or a prostanoid.

TABLE 25 ESC/ERS guidelines: parameters with established importance for assessing disease severity, stability and prognosis in pulmonary arterial hypertension

\begin{tabular}{|c|c|c|}
\hline Better prognosis & Determinants of prognosis & Worse prognosis \\
\hline No & Clinical evidence of RV failure & Yes \\
\hline Slow & Rate of progression of symptoms & Rapid \\
\hline No & Syncope & Yes \\
\hline I, II & WHO FC & IV \\
\hline Longer $(>500 \mathrm{~m})^{\#}$ & 6MWT & Shorter (<300 m) \\
\hline Peak $\mathrm{O}_{2}$ consumption $>15 \mathrm{~mL} \cdot \mathrm{min}^{-1} \cdot \mathrm{kg}^{-1}$ & Cardiopulmonary exercise testing & Peak $\mathrm{O}_{2}$ consumption $<12 \mathrm{~mL} \cdot \mathrm{min}^{-1} \cdot \mathrm{kg}^{-1}$ \\
\hline Normal or near-normal & BNP/NT-proBNP plasma levels & Very elevated and rising \\
\hline No pericardial effusion TAPSE ${ }^{\star}>2.0 \mathrm{~cm}$ & Echocardiographic findings & Pericardial effusion TAPSE ${ }^{\bullet}<1.5 \mathrm{~cm}$ \\
\hline Pra $<8 \mathrm{mmHg}$ and $\mathrm{Cl} \geqslant 2.5 \mathrm{~L} \cdot \mathrm{min}^{-1} \cdot \mathrm{m}^{-2}$ & Haemodynamics & Pra $>15 \mathrm{mmHg}$ or $\mathrm{Cl} \leqslant 2.0 \mathrm{~L} \cdot \mathrm{min}^{-1} \cdot \mathrm{m}^{-2}$ \\
\hline
\end{tabular}

RV: right ventricular; WHO FC: World Health Organization functional class; 6MWT: 6-min walk test; BNP: brain natriuretic peptide; NT-proBNP: N-terminal proBNP TAPSE: tricuspid annular plane systolic excursion; Pra: right atrial pressure; $\mathrm{Cl}$ : cardiac index. ${ }^{\#}$ : depending on age; ${ }^{\bullet}$ : TAPSE and pericardial effusion have been selected because they can be measured in the majority of the patients. Reproduced from [17] with permission from the publisher. 


TABLE 26 ESC/ERS guidelines: definition of inadequate
response to pulmonary arterial hypertension
treatments

WHO FC: World Health Organization functional class. Reproduced from [1] with permission from the publisher.

Continuous i.v. epoprostenol is recommended as first-line therapy for WHO functional class IV PAH patients, because of the survival benefit in this subset. In WHO functional class IV patients, initial combination therapy should also be considered.

\section{CASE 10: INADEQUATE RESPONSE TO PAH THERAPY \\ Case report}

A previously healthy 39-yr-old female presented to her local hospital with a 1-month history of progressive dyspnoea associated with exercise-induced palpitations. She reported that her symptoms had begun approximately 1 month after the birth of her third child. Initial transthoracic echocardiography demonstrated enlarged right heart chambers with estimated systolic Ppa $100 \mathrm{mmHg}$ without evidence of intracardiac shunt. She was referred to an expert centre for further evaluation. Initial RHC confirmed severe pre-capillary $\mathrm{PH}\left(\bar{P}_{\text {pa }} 55 \mathrm{mmHg}\right.$, PVR $1,250 \mathrm{dyn} \cdot \mathrm{s} \cdot \mathrm{cm}^{-5}$, CI $2.0 \mathrm{~L} \cdot \mathrm{min}^{-1} \cdot \mathrm{m}^{-2}$; table 24) without acute vasodilator response. A diagnosis of idiopathic PAH was made after additional investigations for associated causes of $\mathrm{PH}$ were negative. As she was deemed to be in functional class III, with a baseline 6MWD of $519 \mathrm{~m}$, oral endothelin antagonist therapy was initiated.

When the patient was reassessed after 4 months of treatment, she was still in functional class III with a similar 6MWD and haemodynamic profile that showed only a modest improvement (table 24). Because of a lack of improvement in either subjective or objective parameters, a decision was made to add oral PDE-5 inhibitor therapy. At subsequent re-evaluation 6 months after this therapeutic modification, there was both a clinical worsening (80 $\mathrm{m}$ reduction in 6MWD) and haemodynamic deterioration (increased $\bar{P}_{\text {pa }}$ and PVR, with associated significant reduction in CI; table 24). In view of this objectively defined deterioration in spite of dual oral targeted therapy, continuous i.v. prostacyclin was added to her treatment regimen. At the next assessment after 6 months of this threedrug combination approach, a marked clinical and haemodynamic improvement was observed (table 24). 3 yrs after initiation of triple therapy the patient is alive and well.

\section{Commentary: relevance to ESC/ERS guidelines}

Regular evaluation of patients with $\mathrm{PAH}$ should focus on variables with established prognostic importance, as outlined above. Treatment decisions should be based on parameters that reflect symptoms and exercise capacity and that are relevant in terms of predicting outcome. Table 25 lists several parameters of known prognostic importance that are widely used as follow-up tools. Patients with better or worse prognosis are separated by an intermediate group for which prognostication is more difficult.

Based on the clinical, noninvasive and invasive findings the clinical condition of a patient can be defined as stable and satisfactory, stable but not satisfactory, unstable and deteriorating, as follows. 1) Stable and satisfactory. Patients in this condition should fulfil the majority of the findings listed in the "better prognosis" column. 2) Stable and not satisfactory. This is a patient who, although stable, has not achieved the status that the patient and treating physician would consider desirable. Some of the limits described above for a stable and satisfactory condition and included in the "better prognosis" column are not fulfilled. These patients require re-evaluation and consideration for additional or different treatment following full assessment. 3) Unstable and deteriorating. Patients in this condition fulfil the majority of the findings listed in the "worse prognosis" column.

A goal-oriented treatment strategy is recommended in patients with PAH. Treatment goals for $\mathrm{PAH}$ patients that may be

\begin{tabular}{|c|c|c|c|c|c|}
\hline \multirow[t]{2}{*}{ TABLE 27} & \multicolumn{5}{|c|}{$\begin{array}{l}\text { ESC/ERS guidelines: suggested assessments and timing for the follow-up of patients with pulmonary arterial } \\
\text { hypertension }\end{array}$} \\
\hline & & $\begin{array}{c}\text { At baseline } \\
\text { (prior to therapy) }\end{array}$ & Every 3-6 months ${ }^{\#}$ & $\begin{array}{l}\text { 3-6 months after initiation } \\
\text { or changes in therapy }\end{array}$ & In case of clinical worsening \\
\hline \multicolumn{2}{|c|}{ Clinical assessment WHO FC/ECG } & $x$ & $x$ & $x$ & $x$ \\
\hline \multicolumn{2}{|c|}{$6 M W T^{\circ}$} & $x$ & $x$ & $x$ & $x$ \\
\hline \multicolumn{2}{|c|}{ BNP/NT-proBNP } & $x$ & $x$ & $x$ & $x$ \\
\hline \multicolumn{2}{|c|}{ Echocardiography } & $x$ & & $x$ & $x$ \\
\hline \multicolumn{2}{|c|}{ RHC } & $x^{+}$ & & $x^{\S}$ & $x^{\S}$ \\
\hline
\end{tabular}

WHO-FC: World Health Organization functional class; X: assessment is suggested; 6MWT: 6-min walk test; BNP: brain natriuretic peptide; NT-proBNP: N-terminal proBNP; RHC: right heart catheterisation. ${ }^{\#}$ : intervals should to be adjusted to individual patients needs; ${ }^{\natural}$ : usually one of the two exercise tests is performed; ${ }^{+}$: is recommended (table 20); \$. should be performed (table 20). Reproduced from [1] with permission from the publisher. 

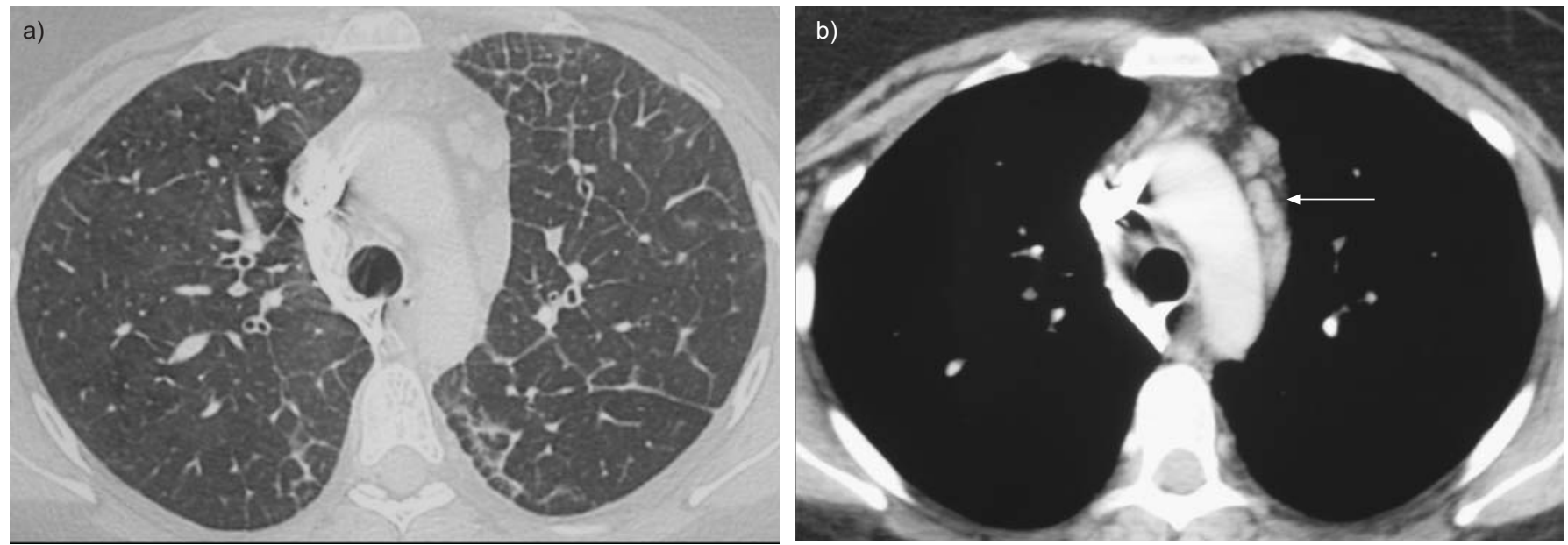

FIGURE 7. High-resolution computed tomography in a pulmonary veno-occlusive disease patient showing septal lines and ground-glass opacities (a) associated with mediastinal lymph node enlargement (arrow, b)

considered are those listed in the "stable and satisfactory definition" and in the "better prognosis" column.

In the case of inadequate clinical response (table 26), sequential combination therapy should be considered. Combination therapy can include either an endothelin receptor agonist plus a PDE-5 inhibitor, or a prostanoid plus an endothelin receptor agonist, or a prostanoid plus a PDE-5 inhibitor. Appropriate protocols for timing and dosing to limit possible side-effects of the combination have still to be defined. In expert centres triple combination therapy is also considered.

Balloon atrial septostomy and/or lung transplantation are indicated for $\mathrm{PAH}$ with inadequate clinical response despite optimal medical therapy or where medical treatments are unavailable. These procedures should be performed only in experienced centres.

Suggested follow-up strategies for patients with $\mathrm{PAH}$ are reported in table 27 .

\section{CASE 11: PULMONARY VENO-OCCLUSIVE DISEASE Case report}

A previously healthy 37-yr-old female cigarette smoker (8 packyrs) was referred with a 2-month history of intermittent chest pain on a background of a 2-yr history of progressive dyspnoea. On admission, the patient was in WHO functional class IV; physical examination revealed a loud pulmonic component to the second heart sound and normal pulmonary auscultation. ECG demonstrated complete right bundle branch block. Arterial blood gases showed severe hypoxaemia at rest (arterial oxygen tension $\left.\left(\mathrm{Pa}, \mathrm{O}_{2}\right) 5.8 \mathrm{kPa}\right)$ while PFTs found normal values for forced expiratory volume in $1 \mathrm{~s}$, forced vital capacity and total lung capacity, associated with a moderate impairment of DL,CO (52\%). Echocardiography estimated systolic Ppa at $72 \mathrm{mmHg}$. RHC confirmed severe pre-capillary $\mathrm{PH}$ with normal left heart filling pressures $\left(\bar{P}_{\text {pa }} 68 \mathrm{mmHg}\right.$, right atrial pressure $9 \mathrm{mmHg}$, Ppcw $11 \mathrm{mmHg}$, CI $2.27 \mathrm{~L} \cdot \mathrm{min}^{-1} \cdot \mathrm{m}^{-2}$ and PVR 1,010 dyn $\cdot \mathrm{s} \cdot \mathrm{cm}^{-5}$ ). Acute vasodilatator testing with nitric oxide showed a degree of vasoreactivity that was insufficient to fulfil criteria for an acute vasodilator response (decrease in $\bar{P}_{\text {pa }}$ to $56 \mathrm{mmHg}$ without change in $\mathrm{CI}$ ). $6 \mathrm{MWD}$ was not feasible. Ventilation/perfusion lung scintigraphy found multiple mismatched subsegmentary perfusion defects. HRCT showed patchy areas of centrilobular ground-glass opacification, septal lines and mediastinal lymph node enlargement (fig. 7). This combination of radiological abnormalities associated with low $\mathrm{Pa}_{1} \mathrm{O}_{2}$ at rest and low $D \mathrm{~L}, \mathrm{CO}$ was highly suggestive of a diagnosis of PVOD. Neither surgical nor transbronchial lung biopsy, being contraindicated in suspected PVOD, was performed. The patient was hospitalised in the intensive care unit and treated with oxygen, diuretics and dobutamine. Because of the poor prognosis associated with PVOD, the risk of life-threatening pulmonary oedema with specific $\mathrm{PAH}$ therapy and the requirement for inotropic support in this case, the patient was listed for urgent double-lung transplantation and was transplanted 1 week later. The diagnosis of PVOD was confirmed by pathological assessment of the explanted lungs.

\section{Commentary: relevance to ESC/ERS guidelines}

Both PVOD and PCH are uncommon conditions, but are increasingly recognised as causes of PAH. They have been classified in a specific subgroup (group 1') of the clinical classification for the pathological, clinical and therapeutic differences with the other forms of $\mathrm{PAH}$ included in group 1.

The diagnosis of PVOD can be established with a high probability by the combination of clinical suspicion, physical examination, bronchoscopy and radiological findings. Most patients complain of dyspnoea on exertion and fatigue, a clinical presentation that is indistinguishable from idiopathic PAH. Physical examination may reveal digital clubbing and bibasal crackles on lung auscultation, these being unusual in other forms of PAH. Case series suggest that patients with PVOD are more severely hypoxaemic and have a much lower $D$ L,CO than in other forms of PAH. HRCT scanning is the investigation of choice. Typical findings suggestive of PVOD are the presence of subpleural thickened septal lines, centrilobular ground-glass opacities and mediastinal lymphadenopathy. Because PVOD may be associated with occult alveolar haemorrhage, bronchoscopy with bronchoalveolar lavage may be a useful tool in the diagnostic strategy. This noninvasive approach may avoid lung biopsy in most of the cases. 


\begin{tabular}{|c|c|c|c|}
\hline \multirow{2}{*}{$\begin{array}{l}\text { TABLE } 28 \\
\text { Statement }\end{array}$} & \multicolumn{3}{|c|}{$\begin{array}{l}\text { ESC/ERS guidelines: recommendations for } \\
\text { pulmonary veno-occlusive disease (PVOD) }\end{array}$} \\
\hline & & Class $^{\#}$ & Level" \\
\hline \multicolumn{2}{|c|}{$\begin{array}{l}\text { Referral of patients with PVOD to a transplant centre } \\
\text { for evaluation is indicated as soon as the diagnosis } \\
\text { is established }\end{array}$} & 1 & $C$ \\
\hline \multicolumn{2}{|c|}{$\begin{array}{l}\text { Patients with PVOD should be managed only in } \\
\text { centres with extensive experience in PAH due to } \\
\text { the risk of lung oedema after the initiation of } \\
\text { PAH-specific drug therapy }\end{array}$} & Ila & C \\
\hline
\end{tabular}

Haemodynamic presentation of PVOD is similar to idiopathic PAH. Importantly, $P$ pcw is almost invariably normal because the pathological changes occur in small venulae and do not affect the larger pulmonary veins.

There is no established medical therapy for PVOD. Most importantly, vasodilators and especially prostanoids must be used with great caution because of the high risk of pulmonary oedema (table 28).

There are reports of sustained clinical improvement in individual patients treated with these medications. Therefore, therapy for PVOD should be undertaken only at centres with extensive experience in the management of $\mathrm{PH}$, and patients should be fully informed about the risks.

Atrial septostomy may be considered but is usually limited by hypoxaemia. The only curative therapy for PVOD and $\mathrm{PCH}$ is lung transplantation, and similarly to idiopathic PAH there are no reports of recurrence of disease following transplantation. Patients with PVOD should be referred to a transplant centre for evaluation as soon as the diagnosis is established.

\section{CONCLUSION}

We hope that these real-life cases and their accompanying commentaries have emphasised the high clinical relevance of the ESC and ERS guidelines, which should be largely disseminated and implemented. On this occasion, the authors wish to thank N. Galiè, University of Bologna, Bologna, Italy, who chaired the PH guidelines group, and all task force members, as well as members of the guideline committees from the ESC and the ERS.

\section{SUPPORT STATEMENT}

D.S. O'Callaghan is the recipient of a long-term European Respiratory Society Fellowship (number 67). A. Redzepi is the recipient of a European Respiratory Society training fellowship (number 365).

\section{STATEMENT OF INTEREST}

D. Montani, X. Jaïs, F. Parent, O. Sitbon and G. Simonneau have relationships with drug companies including Actelion, BayerSchering, GlaxoSmithKline, Pfizer and United Therapeutics. In addition to being an investigator in trials involving these companies, relationships include consultancy services and membership of scientific advisory boards. M. Humbert has relationships with drug companies including AB Science, Actelion, Altair, Amgen, Astrazeneca, Chiesi, GlaxoSmithKline, MSD, Novartis and Pfizer. In addition to being an investigator in trials involving these companies, relationships include consultancy services and membership of scientific advisory boards.

\section{REFERENCES}

1 Galiè N, Hoeper MM, Humbert M, et al. Guidelines for the diagnosis and treatment of pulmonary hypertension. The Task Force for the diagnosis and treatment of pulmonary hypertension of the European Society of Cardiology (ESC) and the European Respiratory Society (ERS), endorsed by the International Society of Heart and Lung Transplantation (ISHLT). Eur Respir J 2009; 34: 1219-1263.

2 Galiè N, Hoeper MM, Humbert M, et al. Guidelines for the diagnosis and treatment of pulmonary hypertension: The Task Force for the diagnosis and treatment of pulmonary hypertension of the European Society of Cardiology (ESC) and the European Respiratory Society (ERS), endorsed by the International Society of Heart and Lung Transplantation (ISHLT). Eur Heart J 2009; 30: 2493-2537.

3 Galiè N, Negro L, Simonneau G. The use of combination therapy in pulmonary arterial hypertension: new developments. Eur Respir Rev 2009; 18: 148-153.

4 Humbert M, Rubin L. Combining evidence and experience in pulmonary hypertension. Eur Respir Rev 2009; 18: 135-136.

5 Gatzoulis M, Alonso-Gonzalez R, Beghetti M. Pulmonary arterial hypertension in paediatric and adult patients with congenital heart disease. Eur Respir Rev 2009; 18: 154-161.

6 Vachiéry J, Coghlan G. Screening for pulmonary arterial hypertension in systemic sclerosis. Eur Respir Rev 2009; 18: 162-169.

7 Montani D, Price LC, Girerd B, et al. Fatal rupture of pulmonary arteriovenous malformation in hereditary haemorragic telangiectasis and severe PAH. Eur Respir Rev 2009; 18: 42-46.

8 Lang IM. Managing chronic thromboembolic pulmonary hypertension: pharmacological treatment options. Eur Respir Rev 2009; 18: 24-28.

9 Humbert M, McLaughlin VV. The 4th World Symposium on Pulmonary Hypertension. Introduction. J Am Coll Cardiol 2009; 54: S1-S2.

10 Souza R, Jardim C. Trends in pulmonary arterial hypertension. Eur Respir Rev 2009; 18: 7-12.

11 Simonneau G, Robbins I, Beghetti M, et al. Updated clinical classification of pulmonary hypertension. J Am Coll Cardiol 2009; 54: S43-S54.

12 Barst RJ, McGoon M, Torbicki A, et al. Diagnosis and differential assessment of pulmonary arterial hypertension. J Am Coll Cardiol 2004; 43: S40-S47.

13 Paulus WJ, Tschope C, Sanderson JE, et al. How to diagnose diastolic heart failure: a consensus statement on the diagnosis of heart failure with normal left ventricular ejection fraction by the Heart Failure and Echocardiography Associations of the European Society of Cardiology. Eur Heart J 2007; 28: 2539-2550.

14 Task Force for Diagnosis and Treatment of Acute and Chronic Heart Failure 2008 of European Society of Cardiology, Dickstein K, Cohen-Solal A, et al. ESC Guidelines for the diagnosis and treatment of acute and chronic heart failure 2008: The Task Force for the Diagnosis and Treatment of Acute and Chronic Heart Failure 2008 of the European Society of Cardiology. Developed in collaboration with the Heart Failure Association of the ESC (HFA) and endorsed by the European Society of Intensive Care Medicine (ESICM). Eur Heart J 2008; 29: 2388-2442.

15 Hoeper M, Barbera JA, Channick R, et al. Diagnosis, assessment, and treatment of non-PAH pulmonary hypertension. J Am Coll Cardiol 2009; 54: S85-S96.

16 Simonneau G, Galiè N, Rubin LJ, et al. Clinical classification of pulmonary hypertension. J Am Coll Cardiol 2004; 43: S5-S12.

17 McLaughlin VV, McGoon MD. Pulmonary arterial hypertension. Circulation 2006; 114: 1417-1431. 